\title{
Recent advances in radiotracers targeting norepinephrine transporter: structural development and radiolabeling improvements
}

\author{
Xinyu Chen $^{1,2,3}$ (D) Takashi Kudo ${ }^{4}$ (D) Constantin Lapa ${ }^{1,3}$ (D) Andreas Buck $^{1}$ (D) Takahiro Higuchi $^{1,2,5}$ (D)
}

Received: 17 January 2020 / Accepted: 21 March 2020 / Published online: 9 April 2020

(c) The Author(s) 2020

\begin{abstract}
The norepinephrine transporter (NET) is a major target for the evaluation of the cardiac sympathetic nerve system in patients with heart failure and Parkinson's disease. It is also used in the therapeutic applications against certain types of neuroendocrine tumors, as exemplified by the clinically used ${ }^{123 / 131}$ I-MIBG as theranostic single-photon emission computed tomography (SPECT) agent. With the development of more advanced positron emission tomography (PET) technology, more radiotracers targeting NET have been reported, with superior temporal and spatial resolutions, along with the possibility of functional and kinetic analysis. More recently, fluorine-18-labelled NET tracers have drawn increasing attentions from researchers, due to their longer radiological half-life relative to carbon-11 (110 min vs. $20 \mathrm{~min}$ ), reduced dependence on on-site cyclotrons, and flexibility in the design of novel tracer structures. In the heart, certain NET tracers provide integral diagnostic information on sympathetic innervation and the nerve status. In the central nervous system, such radiotracers can reveal NET distribution and density in pathological conditions. Most radiotracers targeting cardiac NET-function for the cardiac application consistent of derivatives of either norepinephrine or MIBG with its benzylguanidine core structure, e.g. ${ }^{11} \mathrm{C}-\mathrm{HED}$ and ${ }^{18} \mathrm{~F}-\mathrm{L}$ MI1 195. In contrast, all NET tracers used in central nervous system applications are derived from clinically used antidepressants. Lastly, possible applications of NET as selective tracers over organic cation transporters (OCTs) in the kidneys and other organs controlled by sympathetic nervous system will also be discussed.
\end{abstract}

Keywords Norepinephrine transporter $\cdot$ Benzylguanidine $\cdot$ Phenethylguanidine $\cdot$ Antidepressant $\cdot$ Organic cation transporter

Electronic supplementary material The online version of this article (https://doi.org/10.1007/s00702-020-02180-4) contains supplementary material, which is available to authorized users.

Xinyu Chen

chen_x@ukw.de

$\triangle$ Takahiro Higuchi

higuchi_t@ukw.com

1 Department of Nuclear Medicine, University Hospital of Würzburg, Oberdürrbacher Str. 6, 97080 Würzburg, Germany

2 Comprehensive Heart Failure Center, University Hospital of Würzburg, Würzburg, Germany

3 Department of Nuclear Medicine, University Hospital of Augsburg, Augsburg, Germany

4 Department of Radioisotope Medicine, Atomic Bomb Disease Institute, Nagasaki University, Nagasaki, Japan

5 Graduate School of Medicine, Dentistry and Pharmaceutical Sciences, Okayama University, Okayama, Japan

\section{Abbreviations}

1TC

5-HTT

$\mathrm{AD}$

ADHD

ADMIRE-HF

AF78

AFBG

ASV

BAT

BBB

$\mathrm{BP}_{\mathrm{ND}}$

C6-hNET

$\mathrm{CHF}$

CNS

COMT
One-tissue compartment

5-Hydroxytryptamine transporter, also SERT

Alzheimer's disease

Attention-deficit hyperactivity disorder

ADreview Myocardial Imaging for Risk

Evaluation in Heart Failure

1-(3-Fluoro-4-(3-fluoropropoxy)phene-

thyl)guanidine

(3-Astato-4-fluorobenzyl)guanidine

Adaptive servo-ventilation

Brown adipose tissue

Blood-brain barrier

Nondisplaceable binding potential

Rat C6 glioma cells stably transfected with the human NET

Congestive heart failure

Central nervous system

Catechol- $O$-methyl transferase 


$\begin{array}{ll}\text { DMI } & \text { Desipramine } \\ \text { EDTA } & \text { Ethylenediaminetetraacetic acid } \\ \text { FDG } & \text { Fludeoxyglucose } \\ \text { FIBG } & \text { 4-Fluoro-3-iodobenzylguanidine } \\ \text { FMeNER-D2 } & \begin{array}{l}\text { 2-((S)-(2-(fluoro)methoxy-d2)phenoxy) } \\ \text { (phenyl)methyl)morpholine }\end{array} \\ \text { FPOIBG } & \text { 4-Fluoropropoxy-3-iodobenzylguanidine } \\ \text { GMO } & \text { N-Guanyl-meta-octopamine } \\ \text { H/B } & \text { Heart-to-blood } \\ \text { H/L } & \text { Heart-to-liver } \\ \text { HED } & \text { Hydroxyephedrine } \\ \text { HF } & \text { Heart failure } \\ \text { HFpEF } & \text { Heart failure with preserved left ven- } \\ & \text { tricular ejection fraction } \\ \text { HIBG } & \text { 4-Hydroxy-3-iodobenzylguanidine } \\ \text { ICD } & \text { Implantation of/implantable cardioverter } \\ & \text { defibrillators } \\ \text { LMI1195 } & N \text {-[3-Bromo-4-(3-fluoro-propoxy)-ben- } \\ & \text { zyl]guanidine } \\ \text { LV } & \text { Left ventricular } \\ \text { MA1 } & \text { Multilinear analysis 1 } \\ \text { MAO } & \text { Monoamine oxidase } \\ \text { Me@HAPTHI } & \text { (S)-1-(3-hydroxy-4-(methylamino)butyl)- }\end{array}$

Me@HAPTHI (S)-1-(3-hydroxy-4-(methylamino)butyl)3-phenyl-1,3-dihydrobenzo[c][1,2,5] thiadiazole 2,2- dioxide

MBF

MDD

MFBG

MHPG

MIBG

MRB

$\mathrm{NE}$

NET

NHP

NS12137

OCTs

PCC

PD

PET

PFBG

PGL

$\mathrm{PhB}$

PHPG

RI

ROIs

SERT

SNS

SPECT

$\mathrm{SUV}_{\max }$

VAMT2
Myocardial blood flow

Major depressive disorder

meta-Fluorobenzylguanidine

4-Fluoro- $m$-hydroxyphenethylguanidine

meta-Iodobenzylguanidine

(S,S)-O-methyl-reboxetine

Norepinephrine

Norepinephrine transporter

Nonhuman primate

Exo-3-[(6-fluoro-2-pyridyl)

oxy]-8-azabicyclo[3.2.1]-octane

Organic cation transporters

Pheochromocytoma

Parkinson's disease

Positron emission tomography

para-Fluorobenzylguanidine

Paraganglioma

Phenoxybenzamine

3-Fluoro- $p$-hydroxyphenethylguanidine

Retention index

Regions of interest

Serotonin transporter, also 5-HTT

Sympathetic nervous system

Single-photon emission computed tomography

Maximum standardized uptake value

Vesicular monoamine transporter 2
$V_{\mathrm{T}} \quad$ Volume of distribution

WAT White adipose tissue

\section{Introduction}

The norepinephrine transporter (NET) serves as the main mechanism for terminating noradrenergic signaling at the synaptic gap and is essential for the reuptake of the neurotransmitter norepinephrine (NE), as well as the extraction of radiotracers targeting NET both in the central nervous system (CNS) and peripheral sympathetic nervous system (SNS). First, it is one of the main targets for pharmacological intervention of related diseases, especially in the CNS. Drugs targeting NET are therapeutically used in the treatment of disorders including depression, attention-deficit hyperactivity disorder (ADHD), and feeding disturbances (Bönisch and Brüss 2006). Second, in common cardiac diseases, such as congestive heart failure (CHF) and ischemia, the cardiac SNS appears to be malfunctioning (Schroeder and Jordan 2012). Sympathetic innervation and function, as represented by the uptake kinetics of NET tracers, is used as a parameter for the diagnosis of heart diseases. Third, in Parkinson's disease (PD), there is growing evidence that, besides depletion of dopamine, additional loss of noradrenergic neurons could also be involved in the clinical expression of motor symptoms (Delaville et al. 2011). Thus, NET is used as a marker to reveal the neurodegeneration and to diagnose parkinsonism. Lastly, due to the specific overexpression/up-regulation of NET in certain neuroendocrine tumors, radiolabeled compounds could also be used for chemotherapy, as seen with the use of currently the only clinically utilized NET ligand, ${ }^{123 / 131}$ I-meta-iodobenzylguanidine $\left({ }^{123 / 131} \mathrm{I}-\mathrm{MIBG}\right)$, against neuroendocrine tumors. Physiologically, the extracted NEs are stably stored in the storage vesicles within the presynaptic neurons, shielding them from metabolism by monoamine oxidase (MAO). This mechanism is crucial for the diagnostic applications, as it reflects the systemic distribution and/or regional expression of NET in pathophysiological conditions. The current review focuses on the introduction of recent developments in NETtargeting radiotracers for both cardiac and CNS diagnostic applications using either single-photon emission computed tomography (SPECT) or positron emission tomography (PET) technology. All the chemical structures of the radiotracers listed in this review are illustrated in Fig. 1, with a particular emphasis on advantageous fluorine-18-labeled ones. Radiotracers targeting cardiac NET are mainly developed from benzylguanidine or metaraminol, which are metabolically stable against MAO, while radiotracers for CNS imaging are derivatives of known NET-selective antidepressants. The discussion will not only examine their potential applications in HF, tumor diagnosis, and CNS disorders, but 
A<smiles>NCC(O)c1ccc(O)c(O)c1</smiles>

Norepinephrine<smiles>N=C(N)NCc1cccc(Br)c1</smiles>

123I-MIBG<smiles>N=C(N)NCc1ccc(F)c(I)c1</smiles>

${ }^{18}$ F-FIBG<smiles>N=C(N)NCCc1ccc(F)c(O)c1</smiles>

${ }^{18}$ F-4F-MHPG<smiles>C[NH2+]N[C@H](C)[C@H](O)c1cccc(O)c1</smiles>

${ }^{11} \mathrm{C}$-HED

${ }^{18}$ F-MFBG<smiles>N=C(N)NCc1ccc(OCCC[18F])c(I)c1</smiles>

${ }^{18}$ F-FPOIBG<smiles>N=C(N)NCCc1ccc(O)c([18F])c1</smiles><smiles>NCCc1cc(O)c(O)cc1F</smiles><smiles>N=C(N)NCc1ccc(F)cc1</smiles>

${ }^{18}$ F-PFBG<smiles>N=C(N)NCCc1ccc(OCCC[18F])c(F)c1</smiles>

B<smiles>NCCC(c1ccccc1)n1c(=O)n(-c2ccccc2)c2ccccc21</smiles>

${ }^{11}$ C-Me@APPI<smiles>C[C@H](O)CCN1c2ccccc2N(c2ccccc2)S1(=O)=O</smiles><smiles>CCOc1ccccc1OC(c1ccccc1)C1CNCCO1</smiles>

reboxetine<smiles>C[O+]c1ccccc1O</smiles><smiles>C[C@@H](c1ccccc1)C1CNCCO1</smiles>

${ }^{11} \mathrm{C}-\mathrm{MRB}$<smiles>[2H]C(F)(F)Oc1ccccc1O[C@H](c1ccccc1)C1CNCCO1</smiles><smiles>COc1cccc(OCC2CC3CCC(C2)N3)n1</smiles>

${ }^{11}$ C-NS8880<smiles>[18F]c1cccc(OC2CC3CCC(C2)N3)n1</smiles>

${ }^{18} \mathrm{~F}-\mathrm{NS} 12137$
Fig. 1 Currently reported radiotracers targeting NET. a Norepinephrine and NET tracers for cardiac imaging. From a structural point of view, the blue moiety represents the common core structure norfenefrine, dark green represents benzylguanidine core structure, and purple represents phenethylguanidine moiety. Red symbolizes radioactive isotopes (Chen et al. 2015, 2019). b The CNS NET tracers derived from antidepressants. This figure was created using ChemDraw 16 for Mac

Risk Evaluation in Heart Failure" (ADMIRE-HF) study, as well as the follow-up ADMIRE-HF extra study (Travin 2017). Moreover, ${ }^{123}$ I-MIBG is used as a risk stratification tool for potential implantation of cardioverter defibrillators (ICD) in HF patients. The currently recruiting event-driven ADMIRE-ICD trial will provide further insight into its efficacy in patient management and determine which patients benefits the most from the implantation (Travin 2017). In addition, a number of malignancies of endocrine origin also feature high NET expression, along with monoamines uptake and storage, which forms the foundation for using ${ }^{131}$ I-MIBG as a therapeutic agent against neuroblastoma and various neuroendocrine tumors (Inaki et al. 2017; Agrawal et al. 2018). Pandit-Taskar and Modak (2017) have presented an overview of NET as a target for theranostics, with a particular focus on the current role and broader application of MIBG and its analogues in neuroendocrine tumors. Very recently, based on the clinical study MIP-IB12B (NCT00874614), the Food and Drug Administration of the US has approved ${ }^{131}$ I-MIBG (AZEDRA, Progenics Pharmaceuticals, Inc.) for the anticancer therapy of adult and pediatric patients (12 years and older) with pheochromocytoma (PCC) or paraganglioma (PGL) (Pryma et al. 2019). 
Now, it is on an expanded study to evaluate the safety and tolerability (NCT02961941). In addition, due to the interaction between the sympathetic components of the various organs controlled by autonomic nervous system (e.g. kidney, brain, and periphery), the application of ${ }^{123}$ I-MIBG and analogous NET radiotracers can also be broadened to assess the pathophysiological conditions in extra-cardiac organs, such as renal denervation and PD (Travin 2019). In the last couple of years, MIBG scintigraphy has been considered for use in the diagnosis of early stage parkinsonian disorders. A study involving 600 patients has demonstrated that ${ }^{123}$ I-MIBG has the diagnostic ability to distinguish PD from atypical parkinsonism. Almost half of the patients displayed positive correlation between decreased tracer uptake and PD. These findings demonstrated its sufficient diagnostic accuracy for detecting the early phase of PD (Kawazoe et al. 2019). When diagnosing PD, use of ${ }^{123}$ I-ioflupane SPECT with ${ }^{123}$ I-MIBG cardiac scintigraphy association, has made it possible to achieve the most appropriate diagnosis in over 90\% cases (Niimi et al. 2017; Nuvoli et al. 2018; Okada et al. 2018). In addition, ${ }^{123}$ I-MIBG is also helpful for differentiating Alzheimer's disease (AD) from Lewy Body dementias (Nuvoli et al. 2018). Most recently, a study involving 115 patients indicated a potential role for immediate $(5 \mathrm{~min})$ or early (15 min) acquisition (replacing that of $240 \mathrm{~min}$ ) in PD patients, which paves the way to a faster validation (Frantellizzi et al. 2020).

${ }^{123}$ I-MIBG is the first in the benzylguanidine series of NET tracers with guanidine moieties. It features a chemically polar structure, which ensures its long-term storage in granular vesicles after extraction. Its biological stability against MAO has set up a paradigm for subsequent tracer design. Despite being introduced 30 years ago, its disadvantages as a SPECT radiotracer limit further application. Among these disadvantages are poorer spatial resolution compared to PET, limited sensitivity in small lesions/small sized tumors, the necessity of several scanning protocols, as well as a delay between the tracer administration and result obtainment (Pfluger and Piccardo 2017). Therefore, in the last two decades, PET, rather than SPECT tracers has become the focus of research.

\section{PET tracers targeting NET}

\section{${ }^{11}$ C-HED}

${ }^{11} \mathrm{C}$-Hydroxyephedrine (HED), as one of the first PET tracers targeting NET, has been investigated intensively in Japan and the US, with studies involving a variety of patients confirming its feasibility in quantifying not only regional sympathetic denervation, but also other conditions as well (Fujita et al. 2016; Hiroshima et al. 2017; Aikawa et al. 2017; Wang et al. 2018). Studies by Fujita et al. on ${ }^{11}$ C-HED
PET involving 60 patients with left ventricular (LV) dysfunction as a predictor of all-cause death. Thirteen deceased patients were associated with significantly lower HED retention than those who survived (7.1 vs. 9.0, $p=0.015$ ). This result demonstrated that cardiac sympathetic dysfunction as measured by ${ }^{11} \mathrm{C}$-HED PET (0.762 as retention per unit (/ min) as a hazard ratio) is related to poor survival rate in patients with LV dysfunction, independent of age (Fujita et al. 2016). This is in accordance with prior systematic investigation performed by only two other research groups (Pietilä et al. 2001; Fallavollita et al. 2014). Furthermore, by enrolling ten controls and thirteen patients, it was possible to correlate the ${ }^{11} \mathrm{C}$-HED PET with myocardial blood flow. The correlation coefficient demonstrated a significantly high relationship for both the whole left ventricle and three coronary territories, illustrating the potential of ${ }^{11} \mathrm{C}$-HED for simultaneous assessment of perfusion and neuronal function within a single scan, for the determination of mismatch (Hiroshima et al. 2017). In addition to global assessment, ${ }^{11} \mathrm{C}-\mathrm{HED}$ has also been used for investigating regional sympathetic denervation in HF patients with preserved left ventricular ejection fraction (HFpEF). The results obtained from 34 patients, along with 11 age-matched volunteers without $\mathrm{HF}$, showed the global ${ }^{11} \mathrm{C}$-HED retention index to be significantly lower and more heterogeneous in HFpEF patients than in volunteers $(p<0.01)$. Regional sympathetic denervation is associated with both contractile dysfunction and the extent of myocardial scarring in patients with HFpEF $(p \leq 0.001)$. It is suggested that regional sympathetic denervation may provide an integrated measure of myocardial damage in HFpEF patients (Aikawa et al. 2017). One of the advantages of cardiac imaging using PET tracers is the possibility of performing quantification analysis. Therefore, in an effort to improve and expand the use of kinetic modeling, Wang et al., estimated the myocardiac tissue volume of distribution $\left(V_{\mathrm{T}}\right)$ using both Logan and multilinear analysis 1 (MA1) graphical methods, while comparing with the one-tissue-compartment (1TC) standard model values. Both the MA1 and Logan models exhibited good agreement with 1TC, with similar regional patterns and global median values, as well as good-to-excellent test-retest repeatability (Wang et al. 2018). The Logan model underestimated $V_{\mathrm{T}}$ due to the recognized noise bias. Logan and MA1 both exhibited similar test-retest variability, suggesting that they may be used in addition to $1 \mathrm{TC}$ in the modeling of ${ }^{11} \mathrm{C}$-HED kinetics, with benefits of greater computational simplicity and the ability to mathematically visualize kinetic parameters for better quality assurance (Wang et al. 2018). Wu et al., investigated the reproducibility and repeatability of ${ }^{11} \mathrm{C}$-HED quantification of global cardiac innervation, regional denervation and myocardial blood flow (MBF) in 20 patients. Their results demonstrated a more reliable repeatability with the simple retention index (RI) method as opposed to that of 
the complex $V_{\mathrm{T}}$ in quantitative measurement of both global and regional innervation, supporting the use of RI over $V_{\mathrm{T}}$ for clinical trials in prediction of cause-specific mortality from sudden cardiac arrest (Wu et al. 2019). Most recently, ${ }^{11} \mathrm{C}$-HED has also been used for the evaluation of adaptive servo-ventilation (ASV) in improving cardiac function of HF patients while comparing to ${ }^{123}$ I-MIBG. Increased heart/mediastinum ratio of ${ }^{123} \mathrm{I}-\mathrm{MIBG}$ imaging along with increased global ${ }^{11} \mathrm{C}$-HED RI confirmed the feasibility of ASV by demonstrating improved sympathetic nerve function (Tokuda et al. 2019). In addition to its clinical application, researchers continue to use ${ }^{11} \mathrm{C}-\mathrm{HED}$ as a preclinical tool for basic research studies, including in a rat model with transient myocardial ischemia. A large defect of ${ }^{11} \mathrm{C}$-HED due to the denervation in ischemic areas has confirmed the increased susceptibility of sympathetic neurons over cardiomyocytes during ischemic injury. It has been shown that the ${ }^{11} \mathrm{C}-\mathrm{HED}$ uptake defect areas in both the subacute and chronic phases after transient ischemia were clearly larger than the perfusion defect areas in the midventricular wall. Partial reinnervation could be observed as the uptake of ${ }^{11} \mathrm{C}$-HED recovered in the subepicardial portion in the chronic phase (Werner et al. 2016). Furthermore, the potential cold mass effect of ${ }^{11} \mathrm{C}$-HED (specific activities $0.2-141.9 \mathrm{GBq} / \mu \mathrm{mol}$ ) in healthy Wistar rats (ranging 0.2-60.4 $\mu \mathrm{g} / \mathrm{kg}$ cold mass) was also investigated, in which a dose-dependent reduction of cardiac ${ }^{11} \mathrm{C}$-HED uptake with different specific activities was observed. With the cold mass dose increased from 0.2, 1,10 to $34 \mu \mathrm{g} / \mathrm{kg}$, a subsequent decrease of tracer uptake in the left ventricular myocardium could be clearly recorded. Time-activity curves demonstrated that at the highest cold dose $(34 \mu \mathrm{g} / \mathrm{kg})$, the washout increased considerably, while both the low-dose curves $(0.2$ and $1 \mu \mathrm{g} / \mathrm{kg})$ remained relatively stable (Werner et al. 2018). In addition, in a longitudinal setting, the cardiac uptake of ${ }^{11} \mathrm{C}-\mathrm{HED}$ in rat hearts reduced from M5, M11 to M15, while ${ }^{18} \mathrm{~F}$-Fludeoxyglucose $\left({ }^{18} \mathrm{~F}-\mathrm{FDG}\right)$ uptake remained stable during the same time period, indicating preserved myocardial viability. As has been previously reported, when compared to ${ }^{123} \mathrm{I}-\mathrm{MIBG}$, the cardiac uptake of ${ }^{11} \mathrm{C}-\mathrm{HED}$ is at equilibrium and relies on the continuous leaking-reuptaking pathway by NET (Werner et al. 2015). Accordingly, an age-related deterioration of NET functionality might explain these findings, which are in accordance with results reported in human studies using other NET tracers (Tsuchimochi et al. 1995; Li et al. 2003).

As a radiotracer targeting NET, the applications of ${ }^{11} \mathrm{C}$ HED are not only limited to the cardiac conditions such as HF. Wong et al. (2017) investigated the regional patterns of cardiac sympathetic denervation in PD using ${ }^{11} \mathrm{C}$-HED PET and determined the denervation rate of 39 patients. Their findings revealed the heterogeneity of cardiac sympathetic denervation in PD. Over a 2-year interval, progressive decline occurred at a modest rate (as observed by
${ }^{11} \mathrm{C}$-HED PET scans), with a regional preferential pattern, consistent with ${ }^{18} \mathrm{~F}$-6-fluorodopamine results. In addition, similar to the application of ${ }^{123}$ I-MIBG in the diagnosis of neuroendocrine tumors, ${ }^{11} \mathrm{C}$-HED could be used as an accurate tool for the diagnosis/ruling out of PCC and PGL in complex clinical scenarios, in contrast to CT/MRI characterization. In a 2019 study by Vyakaranam et al. (2019), ${ }^{11}$ C-HED PET/CT was performed for a cohort of 102 patients, where 19 patients were correctly identified as having PCC, 6 with PGL, and 75 successfully excluded from having either. Moreover, using ${ }^{11} \mathrm{C}$-HED PET as an indicator of sympathetic innervation (expressed as RI\%), it is possible to predict levels of supraclavicular brown adipose tissue (BAT) in lean normal adult subjects. Furthermore, it has been seen that cold-induced decrease in white adipose tissue (WAT) energy expenditure is less pronounced in subjects with high amounts of activated BAT (Muzik et al. 2017).

From structural point of view, ${ }^{11} \mathrm{C}$-HED is derived from the earlier reported metaraminol, which is biologically stable against MAO due to its ephedrine structure, where the $\alpha$ and $N$-methyl groups are able to prevent/slow down the possible enzymatic oxidation/deamination. ${ }^{11} \mathrm{C}$-HED contains two chiral centers. Although both stereoisomers have demonstrated high initial accumulation in murine model hearts, the (+)-isomer features a much faster efflux compared to the (-)-isomer, with effluxes of $T_{1 / 2} 2-3 \mathrm{~h}$ vs. 2-3 days, respectively (Van Dort et al. 2000). Therefore, in potential kinetic studies, the (-)-stereoisomer is always used. In addition, due to its specific ephedrine structure, which is dissimilar from the other radiotracers possessing a guanidine moiety, its in vivo storage and release kinetics differ, as has been mentioned above (Werner et al. 2015).

\section{Advantages of fluorine-18 over carbon-11-labeled PET radiotracers}

Over the last two decades, increasing attention has been placed on fluorine-18-labelled PET tracers (whose radioactive half-life is $110 \mathrm{~min}$ ) due to the following advantages over carbon-11-labelled tracers (whose half-life is $20 \mathrm{~min}$ ): (1) it is more cost effective, given the possibility for its distribution from a central cyclotron facility, reducing the requirement of a costly on-site cyclotron; (2) there exists the potential of delayed and prolonged scans due to its longer half-life; (3) spatial resolution in PET imaging is improved as a consequence of its shorter travel distance prior to annihilation, a result of the low positron energy of fluorine-18; (4) it allows for further alternatives and flexibility in novel tracer design, along with the possibility of improving the tracer stability against metabolism at sensitive positions (Kobayashi et al. 2017). As a result, the designing of new 
NET tracers will focus on the use of fluorine-18 for subsequent development as to take the full advantages of PET imaging technology (Fig. 1a).

\section{${ }^{18}$ F-6F-dopamine}

${ }^{18} \mathrm{~F}-6 \mathrm{~F}$-dopamine is the metabolite of ${ }^{18} \mathrm{~F}-6 \mathrm{~F}$-DOPA and can be transported by NET into cardiac sympathetic nerves. The dosimetry of ${ }^{18} \mathrm{~F}-6 \mathrm{~F}$-dopamine for clinical PET scan has been estimated based on the results from rats and dogs (Goldstein et al. 1991). In initial human study, ${ }^{18} \mathrm{~F}-6 \mathrm{~F}-\mathrm{do}-$ pamine is fast extracted by the sympathetic nerves, where it is translocated into vesicles (Deep et al. 1997). It can provide the neuronal uptake and the turnover of vesicles in the human heart (Goldstein et al. 1993). However, due to its primary amine structure, it undergoes fast metabolism in vivo with only $1-2 \%$ as parent tracer after 10 min injection (Ding et al. 1993). To visualize the cardiac sympathetic neurons, high dose will be needed due to the large excretion from urinary collecting system (Goldstein et al. 1994). After the administration of ${ }^{18} \mathrm{~F}-6 \mathrm{~F}-$ dopamine, the concentration of the tracer in the heart declined bi-exponentially from the peak value. Tyramine chase (injection after radiotracer administration) could increase the speed of tracer washout (Goldstein et al. 1997). Using ${ }^{18} \mathrm{~F}-6 \mathrm{~F}-d o p a m i n e ~ P E T$, it is possible to prove the decreased SNS function in hypertrophic cardiomyopathy patients ( $\mathrm{Li}$ et al. 2000). Goldstein and coworkers have further developed a kinetic model for ${ }^{18} \mathrm{~F}-6 \mathrm{~F}$-dopamine, which can successfully predict the tracer kinetics in vivo under certain pharmacological manipulations (Goldstein et al. 2002).

Similar to MIBG, due to its ability to be taken up by NET, ${ }^{18} \mathrm{~F}-6 \mathrm{~F}$-dopamine is also used for diagnostic localization of PCC with high sensitivity (Pacak et al. 2001), with superior outcome compared to ${ }^{123}$ I-MIBG (Ilias et al. 2003; Mamede et al. 2006; Kaji et al. 2007). In several patient studies, ${ }^{18} \mathrm{~F}-6 \mathrm{~F}$-dopamine showed equal sensitivity to localize nonmetastatic PCC when compared to ${ }^{123} \mathrm{I}-\mathrm{MIBG}$, but much better for metastatic ones (Ilias et al. 2008; Timmers et al. 2009a, b). It is helpful to distinguish between physiological adrenal gland uptake and pathological PCC uptake (Timmers et al. 2007). In patient study with mostly adrenal PGL, ${ }^{18} \mathrm{~F}$-6F-dopamine is recommended over ${ }^{18} \mathrm{~F}$-FDG, ${ }^{123} \mathrm{I}$-MIBG and ${ }^{18} \mathrm{~F}$-DOPA (Timmers et al. 2009a, b), whereas when detecting head and neck PGL, ${ }^{18}$ F-DOPA proved to be the most effective one (King et al. 2011). Other application of ${ }^{18} \mathrm{~F}-6 \mathrm{~F}$-dopamine include imaging proof of denervation in the painful feet of patients with diabetic neuropathy (Tack et al. 2002), detection of medullary thyroid cancer (Gourgiotis et al. 2003), ageing-related cardiac SNS changes ( $\mathrm{Li}$ et al. 2003), cardiac and extra-cardiac sympathetic denervation in PD with orthostatic hypotension patients (Tipre and Goldstein 2005), hypo-innervation in familial dysautonomia
(Goldstein et al. 2008), prediction of PD in at-risk individuals (Goldstein et al. 2018). ${ }^{18} \mathrm{~F}-6 \mathrm{~F}$-dopamine was initially radiolabeled using electrophilic labeling method ${ }^{18} \mathrm{~F}-\mathrm{F}_{2}$ with only $2.6 \%$ radiochemical yield and $13.2 \mathrm{GBq} / \mu \mathrm{mol}$ specific acitivity (Eskola et al. 2012). After changing to a nickelmediated radiofluorination method, the yield was improved to $12 \%$ (Zlatopolskiey et al. 2015). Most recently, the use of iodonium salt as precursor in a one-pot two-step automatic synthesis could increase the yield to $26 \%$ (Vāvere et al. 2018) that allows the clinical trial of pediatric neuroblastoma imaging (IND 138638).

\section{${ }^{18}$ F-MFBG/PFBG}

To investigate the fluorine-18 derivatives of MIBG, two methods have been used to introduce the fluorine directly onto the benzylguanidine core structure: (1) replacing the iodine with fluorine directly to obtain ${ }^{18} \mathrm{~F}$-meta- and parafluorobenzylguanidine $\left({ }^{18} \mathrm{~F}-\mathrm{MFBG} / \mathrm{PFBG}\right.$, Garg et al. 1994); (2) adding an additional fluorine to the MIBG structure to get ${ }^{18} \mathrm{~F}$-(4-fluoro-3-iodobenzyl)guanidine $\left({ }^{18} \mathrm{~F}\right.$-FIBG, Vaidyanathan et al. 1994, 1995). ${ }^{18} \mathrm{~F}-\mathrm{MFBG}$ and PFBG were originally radiolabeled using a 3 -step synthetic scheme. Selective uptake of both ${ }^{18} \mathrm{~F}-\mathrm{MFBG} / \mathrm{PFBG}$ isomers has been observed in mice at similar levels: slightly higher levels of adrenal uptake than in the heart, while the radiochemical yield of PFBG is relatively higher than MFBG (Garg et al. 1994). The specific uptake of ${ }^{18} \mathrm{~F}-\mathrm{MFBG}$ and PFBG were similar when examined in rat $\mathrm{C} 6$ glioma cells stably transfected with the human NET (C6-hNET), but fourfold less than MIBG. PET imaging of ${ }^{18} \mathrm{~F}-\mathrm{MFBG}$ has demonstrated comparable tumor accumulation to the SPECT tracer ${ }^{123}$ I-MIBG, but MFBG showed a significantly more rapid clearance (Zhang et al. 2014a). A follow-up study using five neuroblastoma cell lines and two xenografts expressing different levels of NET confirmed the lower affinity for NET and lower cellular uptake of MFBG than MIBG, but the in vivo imaging and tissue radioactivity concentration measurements still demonstrated higher MFBG xenograft uptake and tumorto-normal organ ratios (Zhang et al. 2014b). Due to the development of iodonium salt as a precursor for the electronrich benzene ring radiofluorination method, the radiolabeling of ${ }^{18} \mathrm{~F}$-MFBG has been optimized to make the last step radiofluorination, followed by the total deprotection of Boc groups from guanidine moiety with an overall radiolabeling time less than 1 hour. The average yield was greatly improved from $10-15 \%$ to $31 \%$ with $>99 \%$ radiochemical purity, which permits the automated production of multidose batches of clinical grade MFBG (Hu et al. 2015). Based on these thorough preclinical evaluations, the first-in-human study was performed in ten patients, which showed excellent in vivo stability and safety as well as a favorable biodistribution with good targeting of lesions that makes it feasible for 
same-day imaging of neuroendocrine tumors. The maximum standardized uptake value $\left(\mathrm{SUV}_{\max }\right)$ of lesions was $8.6 \pm 9.6$ at $1-2 \mathrm{~h}$ and $9.2 \pm 11.4$ at 3-4 $\mathrm{h}$ after injection. It showed a two phases clearance from the blood pool and was primarily excreted from the kidneys. Due to this, the bladder was exposed to the highest and longest amount of radiation exposure faster than ${ }^{123}$ I-MIBG, counting $61-95 \%$ vs $11-26 \%$, respectively, by $3 \mathrm{~h}$ after injection. ${ }^{18} \mathrm{~F}-\mathrm{MFBG}$ demonstrated high promise for imaging in patients, especially for children with neuroblastoma (Pandit-Taskar et al. 2018).

\section{${ }^{18}$ F-FIBG and analogues}

Analogously, Vaidyanathan et al., devised another method for the introduction of the extra fluorine-18 to MIBG, as opposed to replacing iodine, to form ${ }^{18}$ F-FIBG. Similar to the other fluorobenzylguanidine tracers, the original radiolabeling procedure consisted of multiple steps with a long synthesis time $(130 \mathrm{~min})$ and low radiochemical yield (5\% decay corrected) due to the requirement of the electron-withdrawing group cyanide for the successful electrophilic radiofluorination. However, both in vitro binding studies on SK-N-SH human neuroblastoma cells and in vivo tissue distribution studies indicate comparable properties to MIBG (Vaidyanathan et al. 1994). Further in vitro assays of tracer binding were carried out to confirm the NET-specific and energy-dependent uptake mechanisms similar to those of MIBG. A blocking study using desipramine (DMI) in mice has further confirmed the NET specificity by reducing cardiac and adrenal uptake to $57 \%$ and $60 \%$, respectively. Radiation dosimetry calculations also suggested that, as an important advantage, higher doses of ${ }^{18}$ F-FIBG could be administered to patients than ${ }^{124}$ I-MIBG (Vaidyanathan et al. 1995). Presumably due to the encouraging results obtained from ${ }^{18} \mathrm{~F}-\mathrm{FIBG}$, the same research group also reversely examined ${ }^{131}$ I-FIBG and the corresponding alpha-emitter analogue ${ }^{211} \mathrm{At}$-(3-astato4-fluorobenzyl)guanidine ( $\left.{ }^{211} \mathrm{At}-\mathrm{AFBG}\right)$, both of which were synthesized from the same precursor using similar radiolabeling methods with $50-60 \%$ and $65-70 \%$ yield, respectively (Vaidyanathan et al. 1996). Naturally, both ${ }^{131}$ I-FIBG and ${ }^{211}$ At-AFBG demonstrated characteristics comparable to those of their parent compound MIBG in terms of NET-specific uptake in both cell-based and mouse studies. It is noteworthy that both new analogues show higher stability against dehalogenation in mice when compared to ${ }^{131}$ I-MIBG or ${ }^{211}$ At-MABG. They particularly feature lower thyroidal uptake, presumably due to the introduction of fluorine - the strong electron-withdrawing effect of which stabilizes the C-I and C-At bond (Vaidyanathan et al. 1997a, b). Further cell studies suggested that when ${ }^{125}$ I-MIBG and ${ }^{125}$ I-FIBG metabolism occurs, it leads to the same metabolites, but not as the original halobenzylguanidine (Vaidyanathan et al. 2004). As previously reported, one of the main metabolites of MIBG is 4-hydroxy-3-iodobenzylguanidine (HIBG) (Mangner et al. 1986). As a consequence, the 4-fluoro substituent of FIBG greatly slows down the metabolism (i.e. defluorination and oxidation) when compared to MIBG. In a SK$\mathrm{N}-\mathrm{SH}$ cell study, $70 \%$ of radioiodine activity remained from ${ }^{125}$ I-FIBG after 3 days of experiment, compared to just $30 \%$ for ${ }^{125}$ I-MIBG. This offers a positive hint toward future tracer design: the introduction of a fluorine may provide not only the possibility of deriving the known tracer into an ${ }^{18} \mathrm{~F}$-labeled PET tracer without major changes in characteristics, but may also introduce further benefits, such as improving the tracer stability in vivo by preventing the enzymatic degradation. Presumably due to their difficult radiolabeling procedure and low radiochemical yield, these tracers have not drawn much attention from researchers. Most recently, however, again benefiting from the development of iodonium salt as the precursor for electron-rich aromatic radiofluorination, Yamaguchi et al., optimized the radiolabeling of both ${ }^{18} \mathrm{~F}-\mathrm{FIBG}$ and ${ }^{131}$ I-MIBG using a copper-mediated 2-step procedure with a mesityl(aryl)iodonium salt precursor. Their results reconfirm the feasibility of these compounds as diagnostic and therapeutic agents with high and specific accumulation in the PC12 xenograft tumor cells, along with high tumorto-background ratios in mice studies. ${ }^{131}$ I-FIBG displayed a higher and more prolonged retention in tumors when compared to ${ }^{125}$ I-MIBG, which resulted in greater dosedependent delay in tumor growth than with ${ }^{131}$ I-MIBG (Yamaguchi et al. 2018).

\section{${ }^{18}$ F-FPOIBG}

An alternative strategy for the derivation of a fluorine- 18 tracer from MIBG has been to introduce a fluoropropoxyl group onto the MIBG core structure, from which $4-\left[{ }^{18} \mathrm{~F}\right]$ fluoropropoxy-3-iodobenzylguanidine $\left({ }^{18} \mathrm{~F}\right.$-FPOIBG) was synthesized and compared with MIBG in three different NET-expressing cell lines. Uptake studies show that the tracer uptake at $2 \mathrm{~h}$ was, on average, lower than its lead MIBG, counting ${ }^{18} \mathrm{~F}$-FPOIBG with10.2, 38.6, and $13.3 \%$, and ${ }^{125}$ I-MIBG with $57.3 \%, 82.7 \%$, and $66.3 \%$ in SK-NSH, UVW-NAT and SK-N-BE(2c) cells, respectively. However, the corresponding bromine analogue of FPOIBG has demonstrated much higher uptake, with a higher $\mathrm{IC}_{50}$ value than either bromide or MIBG (Vaidyanathan et al. 2015). As a result, although FPOIBG does not provide superior in vivo properties than reported tracers, it offers a hint at the structure-activity relationships (SARs) of the tracers, which may prove useful for further tracer design, such as the intolerant iodine and the introduction of 
3-fluoropropoxyl substitution consistent with $N$-[3-bromo4-(3-fluoro-propoxy)-benzyl]-guanidine (LMI1195).

\section{${ }^{18}$ F-LMI1195}

Prior to ${ }^{18} \mathrm{~F}$-FPOIBG, ${ }^{18} \mathrm{~F}$-LMI1 195 was one of the first fluorine-18-labeled PET tracers derived from MIBG's core structure without the direct introduction of fluorine- 18 onto the benzene ring, avoiding the difficulty of radiofluorination. Different substitution patterns on the benzene ring/ heterocycles, linkers between aromatic and guanidine moieties with or without $\beta$-hydroxyl group, as well as different substituted/integral guanidines have been investigated and patented by Lantheus Medical Imaging (Purohit et al. 2008). The chemical structure of LMI1195 was derived from MIBG with meta-bromine replacing iodine, with an extra para-3-fluoropropoxyl group for convenient radiolabeling and improved radiochemical yield compared to other MIBG derived tracers with direct radiofluorination on the electron-rich benzene ring. In this way, LMI1195 could be labeled from a brosylate precursor and a single-step fluorine-18 displacement reaction followed by HPLC separation (Yu et al. 2011). ${ }^{18}$ F-LMI1 195 has demonstrated comparable in vitro properties to MIBG and more favorable in vivo characteristics than MIBG in both rats and rabbits, with clear and specific cardiac uptake and better heart-to-liver (H/L) ratios than MIBG (Yu et al. 2011). ${ }^{18}$ F-LMI1 195 was used in imaging of regional cardiac sympathetic denervation in the rabbit model due to its high association with NET (Yu et al. 2012). Comparable to either MIBG or HED, LMI1 195 has also showed high and specific accumulation in neuroendocrine tumors in the rat model, and more favorably than the reference MIBG (Gaertner et al. 2013). Following a successful phase 1 clinical trial, in which ${ }^{18}$ F-LMI1 195 has demonstrated cardiac imaging potential with comparable radiation dose and favorable kinetics (Sinusas et al. 2014), it was compared with ${ }^{11} \mathrm{C}$-HED in a recent publication. The preliminary data suggested a highly correlated estimation of cardiac sympathetic innervation for both tracers, whereas ${ }^{18} \mathrm{~F}$-LMI1195 showed significantly elevated heart-to-blood (H/B) ratios when compared to ${ }^{11} \mathrm{C}-\mathrm{HED}$ (Zelt et al. 2018). This leads into further phase 2 clinical trials for the prediction of arrhythmic events and the strategizing of the identification of patients who should receive ICD (NCT03493516).

While using rats and rabbits with and without sympathetic neuronal denervation, ${ }^{18} \mathrm{~F}$-LMI1195 exhibited different uptake mechanisms due to species discrepancies: LMI1195 cardiac uptake did not change in the rat model but was greatly decreased in rabbits following treatment of uptake-1 selective blockade using DMI. This stems from the existence of extra-neuronal uptake (i.e. uptake-2) in the rat heart. A consistent result could be obtained from denervated rabbits and nonhuman primates (NHP), for the reason that in both animals only uptake 1 is responsible for the NET tracer uptake (Yu et al. 2013). Further assessment in rats using the non-selective uptake blocker phenoxybenzamine $(\mathrm{PhB})$ confirmed the existence of both uptake 1 and 2 in rat hearts, where the cardiac uptake of ${ }^{18} \mathrm{~F}$-LMI1 195 could only be reduced by $\mathrm{PhB}$, rather than DMI or saline control (Higuchi et al. 2013). First-pass tracer extraction fraction (EF) and washout were measured in an ex vivo study using isolated rabbit hearts, which is chosen due to comparable tracer uptake patterns in rabbits and humans. Results demonstrated a flow-dependent EF with DMI sensitivity. The irreversible vesicular monoamine transporter blocker reserpine pretreatment was unable to change the EF. Additionally, an electrical stimulation instead of DMI chase (DMI added in washout phase) was able to enhance the tracer washout rate, suggesting that the tracer storage and release mode at the nerve terminal was consistent with NE (Higuchi et al. 2015). The detailed kinetics of LMI11995 at the subcellular level have been confirmed in an in vitro study using both PC12 (vesicle-rich) and SK$\mathrm{N}-\mathrm{SH}$ (vesicle-poor) cell lines expressing NET. Both highconcentration $\mathrm{KCl}$ and reserpine were able to induce tracer washout due to storage turnover, as such an effect could be only observed in vesicle-rich PC12 cells but not in vesiclepoor SK-H-SH cells. Moreover, such KCl-induced spillover could be suppressed by the calcium chelator EDTA, which is consistent with the fact that the tracer release is mediated by a calcium influx resulting from membrane depolarization (Chen et al. 2018). Adding to these findings, a high-resolution autoradiography of rabbit heart slices following administration of both ${ }^{18} \mathrm{~F}$-LMI1195 and ${ }^{201} \mathrm{Tl}$ was performed, from which a homogeneous distribution of the former was observable throughout the LV wall. No significant differences were found when compared to the slightly discrepant transmural distribution of the latter tracer. Should ${ }^{18} \mathrm{~F}$-LMI1195 be used in the clinic, the presented distinct characteristics in the LV distribution pattern should be considered as preliminary work for imaging result evaluation (Werner et al. 2019).

It is crucial that clinicians understand the characteristics of tracer uptake and retention kinetics when deciding on their suitable clinical applications. With this aim, ${ }^{18} \mathrm{~F}$ LMI1195 was compared with ${ }^{123}$ I-MIBG and ${ }^{11} \mathrm{C}$-HED in rabbit hearts, where all three tracers exhibited DMI (pretreatment)-sensitive/neuronal-specific uptake. However, cardiac washout of ${ }^{11} \mathrm{C}$-HED, rather than ${ }^{18} \mathrm{~F}-\mathrm{L}$ MI1195 and ${ }^{123} \mathrm{I}-\mathrm{MIBG}$, was influenced by DMI chase $(1.5 \mathrm{mg} / \mathrm{kg}$ administered $10 \mathrm{~min}$ after tracer injection), indicating a cycle of continuous NET uptake, and a ${ }^{11} \mathrm{C}$-HED release pattern at the nerve terminals, in contrast to the stable vesicle storage of the other two tracers (Werner et al. 2015). Considering the common benzylguanidine core structure of MIBG and LMI1195 (vs. the ephedrine of HED), it is possible to 
combine its chemical structure with its storage kinetics to conclude that the polar guanidine moiety retains the tracers in storage vesicles, whereas the relatively lipophilic monoamine structure of ephedrine can be released from these vesicles either passively or together with vesicle turnover.

\section{${ }^{18}$ F-4F-MHPG and 3F-PHPG}

It is noteworthy that the insensitivity of known tracers to non-severe regional nerve loss delays possible early stage pharmaceutical intervention. Therefore, to overcome the rapid neuronal uptake and blood flow dependency of the mostly benzylguanidine-based radiotracers, and to provide physicians with a NET targeting tracer with more accurate regional denervation estimation, Raffel et al., synthesized over a dozen phenethylguanidine analogues as novel core structure of NET radiotracers, and investigated their neuronal uptake rate in isolated rat hearts. In this study, ${ }^{11} \mathrm{C}$ - $N$-guanyl-m-octopamine $\left({ }^{11} \mathrm{C}\right.$-GMO) showed a slow NET transport rate, with improved myocardial kinetics, when compared to HED. In cosntrast, ${ }^{11} \mathrm{C}$ - $p$-hydroxyphenethylguanidine showed a rapid NET transport rate and rich accumulation in xenograft tumors in mice (Raffel et al. 2007). Further compartmental modeling and Patlak analysis of ${ }^{11} \mathrm{C}$-GMO kinetics in response to different doses of DMI in monkey hearts confirmed stable uptake, along with the possibility for providing robust and sensitive quantitative measurements of regional NET density (Raffel et al. 2013a). Meanwhile, several known tracers were evaluated in C6-hNET cells to determine their transport constants $K_{\mathrm{m}}$ and $V_{\max }$. Results have confirmed a strong linear correlation between NET-mediated neuronal transport rates and their in vitro transport parameters, as given by the ratio $V_{\max } / K_{\mathrm{m}}$. This project provided useful insights into tracer structure design and NET transport constants (Raffel et al. 2013b). Based on this knowledge, ${ }^{18} \mathrm{~F}$-4-fluoro- $m$-hydroxyphenethylguanidine $\left({ }^{18} \mathrm{~F}-4 \mathrm{~F}-\mathrm{MHPG}\right)$ was discovered. It features comparable biodistribution to MIBG and HED in rats, along with slow cardiac uptake and long-term retention kinetics in isolated rat hearts. Further NHP PET study has proved its feasibility for cardiac imaging by allowing for more accurate quantification of regional cardiac sympathetic nerve density (Jang et al. 2013a). A detailed biodistribution study revealed low uptake in the lungs and liver, in addition to high quality and DMI-sensitive cardiac imaging. Uptake in adrenal glands has also proved its potentiality for oncological application (Jang et al. 2013b). With the establishment of the new synthetic approach to ${ }^{18} \mathrm{~F}$-hydroxyphenethylguanidines, ${ }^{18} \mathrm{~F}$-3-fluoro- $p$-hydroxyphenethylguanidine $\left({ }^{18} \mathrm{~F}-3 \mathrm{~F}-\mathrm{PHPG}\right)$, the structural isomer of ${ }^{18} \mathrm{~F}-4 \mathrm{~F}-\mathrm{MHPG}$, has been evaluated (Fig. 1a). In monkey studies, comparable properties between ${ }^{18} \mathrm{~F}-3 \mathrm{~F}-\mathrm{PHPG}$ and ${ }^{18} \mathrm{~F}-4 \mathrm{~F}-\mathrm{MHPG}$ have been demonstrated, showing higher
H/B (4.0 vs. 3.0) but slightly lower H/ L ratio (2.2 vs. 2.5) due to the relatively faster liver clearance of the latter tracer. Fast clearance of these tracers from the blood has been revealed in monkey studies with sulfate as the main metabolite of ${ }^{18} \mathrm{~F}-4 \mathrm{~F}-\mathrm{MHPG}$, but results are yet unclear for ${ }^{18} \mathrm{~F}-3 \mathrm{~F}-\mathrm{PHPG}$. The mean time to $50 \%$ intact radiotracer is 6.7 and $2.3 \mathrm{~min}$ (Jung et al. 2017). As a result, both ${ }^{18} \mathrm{~F}-4 \mathrm{~F}-\mathrm{MHPG}$ and ${ }^{18} \mathrm{~F}-3 \mathrm{~F}-\mathrm{PHPG}$ have been evaluated in healthy human subjects, from which the information of not only the biodistribution and metabolism, but also, more importantly, the potential of quantitative estimates of regional cardiac sympathetic nerve density could be obtained. These results are consistent with the data obtained from the monkey study, with both excellent imaging properties and individual kinetic characteristics, such as different neuronal accumulation time and liver clearance rate (Raffel et al. 2018). A further study involved eight patients with HF who underwent cardiac innervation PET scans with both tracers while using ${ }^{13} \mathrm{~N}$-ammonia as a reference. The results showed that both tracers are able to provide reliable quantitative metrics of regional sympathetic nerve density and could be used to strategize HF patients for ICD placement (Raffel et al. 2017).

Similar to the case of ${ }^{18} \mathrm{~F}-\mathrm{MFBG} / \mathrm{PFBG}$, the radiolabeling of phenethylguanidine tracers started from using radioisotope carbon-11 for preliminary evaluation, to build up the correlation of chemical structures with NET affinity. Due to the aforementioned disadvantages of carbon-11 tracers, however, later stage development mainly focused on fluorine-18-labeled ones, as exemplified by ${ }^{18}$ F-4F-MHPG (Fig. 2). The initial radiofluorination procedure required four steps because of the requirement of the electron-withdrawing group on the benzene ring (Jang et al. 2013a), but was soon simplified to four steps but one pot reaction including the fluorination from 2-thienyl iodonium salt and the following formation of the guanidine moiety (Jang et al. 2013b). Although the method has been improved, multistep radiolabeling is still time consuming with low radiochemical yield that is not suitable for clinical application. As a result, this research group has kept the iodonium salt precursor but used tetra-Boc as protecting groups on the guanidinyl moiety to accomplish two-step-one-pot radiolabeling. The procedure was applied to both ${ }^{18} \mathrm{~F}-4 \mathrm{~F}-\mathrm{MHPG}$ and $3 \mathrm{~F}-\mathrm{PHPG}$, with an average yield of final product up to $7.0 \%$ and $8.0 \%$, respectively (Jung et al. 2017). In exploring new methods that offer higher yield, spirocyclic iodonium ylide rather than 2-thienyl iodonium salt precursor has been used due to the even higher electron density offered by the former moiety, which could lead to higher yield. Under optimized automated reaction conditions, the yield increased threefold, averaging $7.8 \%$, which the authors claimed being well 


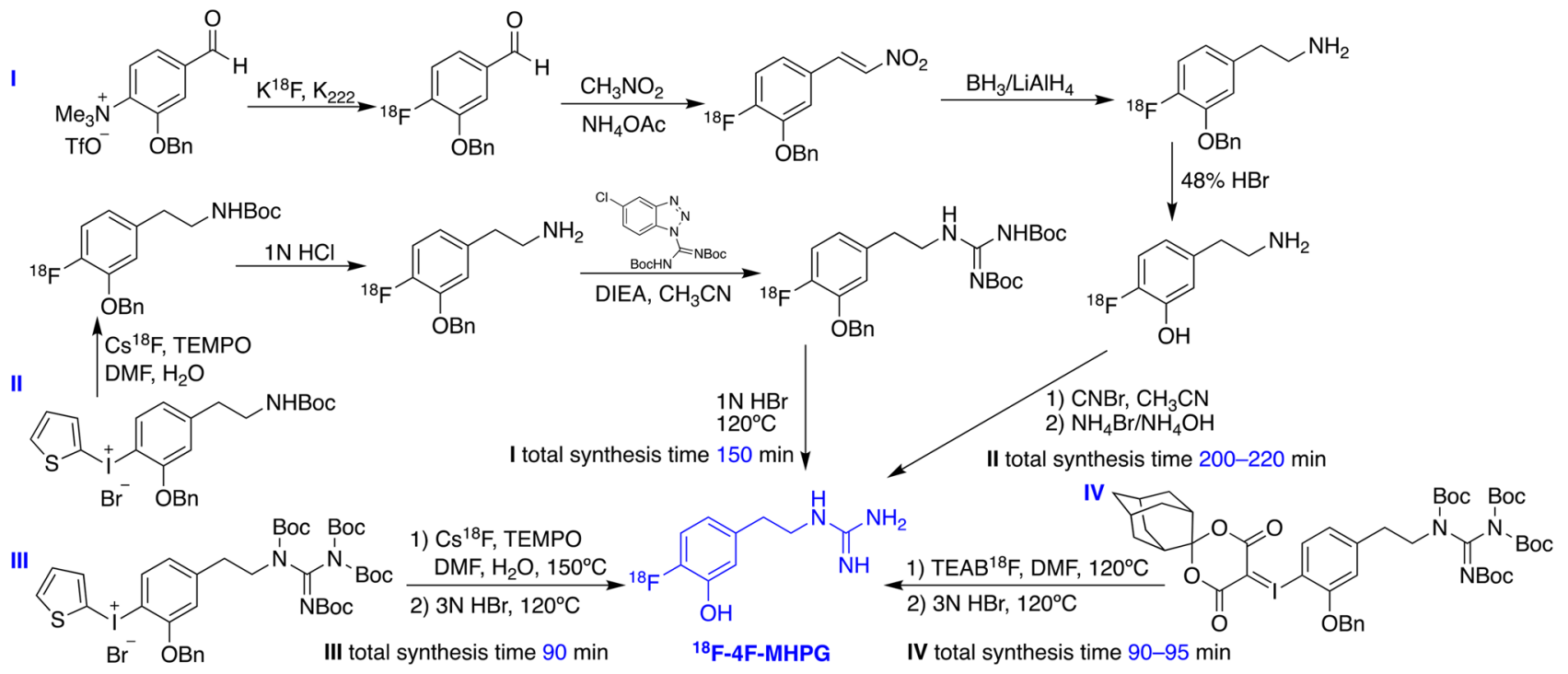

Fig. 2 Development of the synthetic scheme for the radiolabeling of ${ }^{18}$ F-4F-MHPG (Jang et al. 2013a, b; Jung et al. 2017, 2019). This figure was created using ChemDraw 16 for Mac

suited to on-site production for clinical PET studies (Jung et al. 2019).

\section{${ }^{18}$ F-AF78}

Although ${ }^{18}$ F-4F-MFBG/3F-PFBG and ${ }^{18}$ F-FIBG are superior MIBG analogues, their potential clinical applications are limited due to the nature of their chemical structures-the direct radiofluorination on the electron-rich benzene ring is normally not suitable for single-step fluorine-18-labelling. Consequently, a long and demanding radiolabeling procedure along with low radiochemical yield has made further development challenging. To investigate the relationships between the chemical structures of radiotracers and their affinity for NET, our research group has recently developed a new NET-targeting PET tracer: ${ }^{18} \mathrm{~F}-1$-(3-fluoro-4-(3fluoropropoxy)phenethyl)guanidine $\left({ }^{18} \mathrm{~F}-\mathrm{AF} 78\right)$. It bears a phenethylguanidine core structure of ${ }^{18} \mathrm{~F}-3 \mathrm{~F}-\mathrm{PHPG}$ for potential slow uptake kinetics, but with an easier radiolabeling procedure and a high yield $(27 \%)$ as a result of the introduction of a 3-fluoropropoxy substitution-a strategy to develop ${ }^{18} \mathrm{~F}$-LMI1 195 from ${ }^{123}$ I-MIBG as mentioned above (Chen et al. 2019). Cell uptake studies of ${ }^{18} \mathrm{~F}$-AF78 have demonstrated an almost identical affinity for NET as NE and MIBG. Both ex vivo autoradiography of the rat heart and in vivo imaging in rats showed homogeneous and specific cardiac uptake throughout the left ventricular wall (Fig. 3). High $\mathrm{H} / \mathrm{B}$ and $\mathrm{H} / \mathrm{L}$ ratios $(12.54 \pm 0.53$ and $6.14 \pm 0.35$ ) have also been observed (Chen et al. 2019), and are comparable to those of ${ }^{123}$ I-MIBG $(11.91 \pm 1.60$ and $2.42 \pm 0.41)$ and ${ }^{18} \mathrm{~F}-\mathrm{LM} 1195(15.56 \pm 3.61$ and $6.21 \pm 1.68)$ (Yu et al. 2011). Time-activity curves of ${ }^{18} \mathrm{~F}$-AF78 in rats have demonstrated stable and long-term cardiac uptake with favorable H/L ratios following $10 \mathrm{~min}$ of tracer injection, due to the fast liver uptake washout (Fig. 3). Currently, the evaluation of AF78 in different animal species is still ongoing for further in vivo characteristics.

Of note, while developing AF78 from 3F-PHPG, its isomer AF51, the corresponding 3-fluoropropoxy derivative of 4F-MHPG, was also synthesized and evaluated in cell uptake assay as well. It demonstrated a great loss of NET affinity, which provides an insight into the SARs of these NE-derived tracers. To combine the drop of activity of derivation from MIBG to FPOIBG as mentioned above, a substituent larger than iodine on the meta-position would not be tolerable. Consequently, a loss of activity due to the introduction of a 3-fluoropropyl group to 4F-MHPG would be reasonably explained. The reason for choosing 3-fluoropropyl over 2-fluoroethyl is its in vivo stability, as the latter metabolizes faster through defluorination (Kuchar and Mamat 2015). Possible byproduct, such as the formation of vinyl from precursors during radiofluorination, could also be prevented. Furthermore, the ether that substitutes the phenol might change the kinetics and metabolism of the radiotracer in vivo, as it has been proved that one of the major metabolites of 4F-MHPG is the sulfate of the phenol (Jang et al. 2013b). In addition, ether is more stable against oxidation than phenol, which might be the case of the presumable metabolite of 3F-PHPG (Jung et al. 2017). Lastly, cardiac uptake may be also related to the chemical properties of these radiotracers. For example, LogP, or polar surface area, which can be determined by comparing the biodistribution data of 4F-MHPG with MIBG and HED (Jang et al. 2013a). Of note, when evaluating the biodistribution and kinetics 

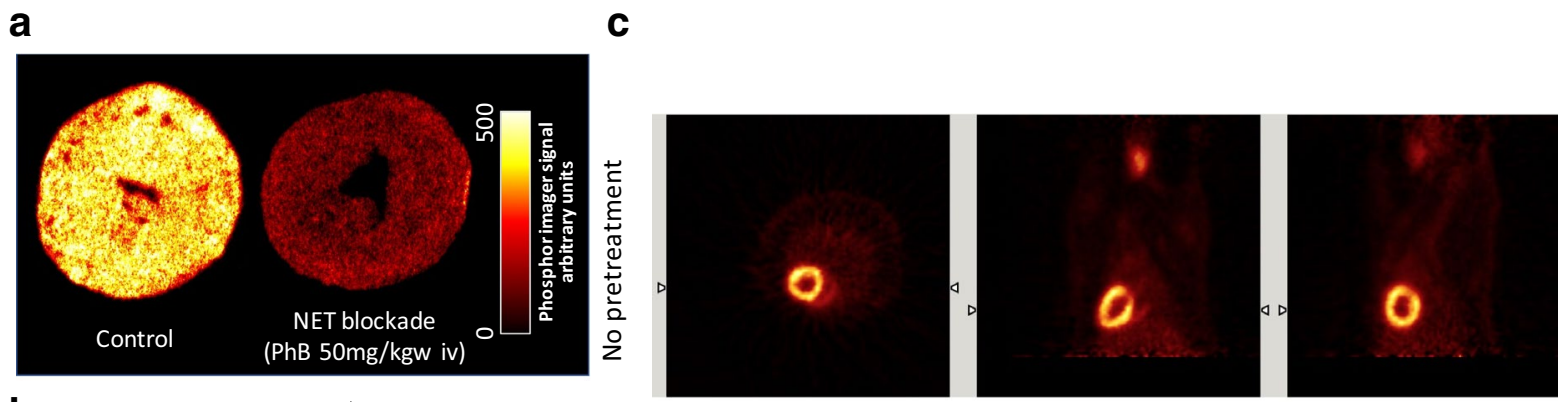

$\% \mathrm{ID} / \mathrm{cm}^{3}$

b

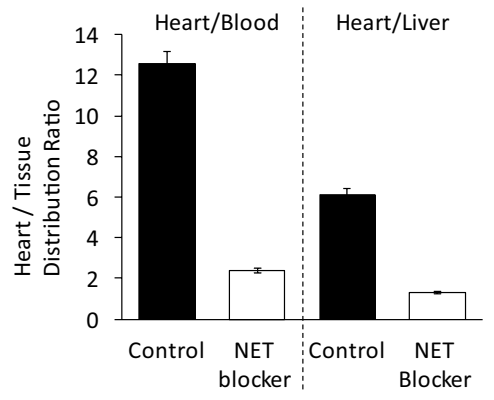

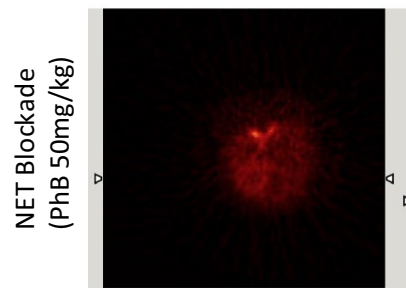

Transverse

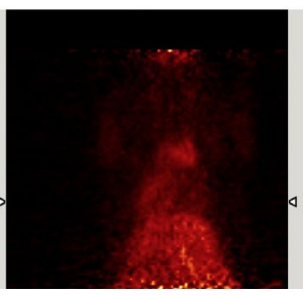

Coronal

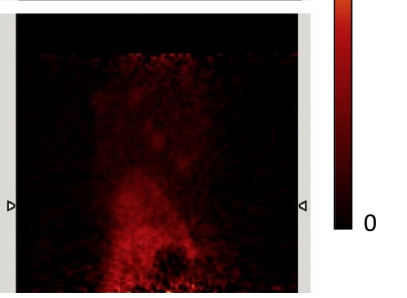

Sagittal
Fig. 3 a Autoradiography of left ventricular short axis slices from rats following administration of ${ }^{18} \mathrm{~F}$-AF78 with (right) and without (left) NET blockade. b Tissue distribution ratios of ${ }^{18} \mathrm{~F}$-AF78 with (hollow column) and without (solid) NET blockade. c Static PET

of ${ }^{18}$ F-AF78 in different animal species, cardiac uptake showed significant differences (unpublished data): it showed different modes of cardiac uptake in animals with only the uptake-1 mechanism, i.e. the uptake can be fully blocked by DMI; and those present both uptake-1 and uptake-2/extraneuronal uptake, where the radiotracer uptake can only be fully blocked by $\mathrm{PhB}$. These results are in accordance with the data obtained from assessing ${ }^{123} \mathrm{I}-\mathrm{MIBG},{ }^{18} \mathrm{~F}$-LMI1 195 and ${ }^{18} \mathrm{~F}-\mathrm{MHPG} / \mathrm{PHPG}$ in different animal models (Rischpler et al. 2013; Higuchi et al. 2013; Jang et al. 2013b; Jung et al. 2017): these radiotracers would be preferably taken up in the heart via uptake-2/extra-neuronal uptake mechanism in animals, such as rats and pigs, where both uptake- 1 and -2 mechanisms present. In contrast, in uptake-1 dominant animals, such as rabbits and monkeys, as well as in humans, these tracers are primarily taken up in the heart via NETmediated uptake-1 mechanisms.

\section{Radiotracers targeting NET in central nervous system}

As mentioned in the introduction section, malfunction of the noradrenergic system in CNS also plays an important role in the process of neurodegenerative diseases, depression, ADHD, and obesity (Borodovitsyna et al. 2017). Therefore, it is conceivable that NET-targeting radiotracers could be used to monitor the function of the noradrenergic system in the CNS, provide diagnostic information concerning the images of the uptake of ${ }^{18} \mathrm{~F}-\mathrm{AF} 78$ in rats with (bottom) and without (top) NET blockade 10 min before radiotracer administration (Chen et al. 2019). This figure was created using Microsoft PowerPoint version 15.38 for Mac then pasted as PDF format into Word file

process of these diseases, and instruct therapeutic applications. However, although all the abovementioned NET-targeting radiotracers can be used for peripheral SNS imaging, they are unable to penetrate the blood-brain barrier (BBB), most probably due to their polar structures with guanidine moieties. As a result, several NET-targeting and BBB-penetrating radiotracers have been developed based on clinically used and NET-selective antidepressants.

\section{${ }^{11} \mathrm{C}-\mathrm{ME} @ H A P T H I$}

Rami-Mark et al. (2013) reported a scaffold using a benzothiadiazole core structure (Fig. 1b) to obtain (S)-1(3-hydroxy-4-([ $\left.{ }^{11} \mathrm{C}\right]$ methylamino)butyl)-3-phenyl-1,3dihydrobenzo[c] $[1,2,5]$ thiadiazole 2,2-dioxide $\left({ }^{11} \mathrm{C}-\mathrm{Me} @\right.$ HAPTHI) based on their previously reported ${ }^{11} \mathrm{C}-\mathrm{Me} @$ APPI. Following successful preparation and radiolabeling, it has displayed good affinity and selectivity for NET over the dopamine transporter (DAT) and serotonin transporter (SERT or 5-HTT), which is crucial for the accuracy of CNS imaging. It is expected to pass the BBB based on the in vitro data. Furthermore, the tracer shows excellent metabolic stability in human liver microsomes with $>99 \%$ intact after 60 min incubation. Autoradiography on human brain tissue has revealed NET-specific uptake in NETrich regions (Rami-Mark et al. 2015). Notably, in addition to CNS uptake, significant cardiac uptake of ${ }^{11} \mathrm{C}-\mathrm{Me} @$ HAPTHI has been observed, albeit with a more lipophilic 
chemical structure than abovementioned radiotracers. After transient ischemia, reduced ${ }^{11} \mathrm{C}-\mathrm{Me} @$ HAPTHI uptake was detected in rat hearts from day 1 to 4 weeks, confirmed by an increased uptake ratio of ischemic area to the non-ischemic area, and increased uptake ratio of non-ischemic area to the blood pool. A reduced ratio of cardiac uptake to blood radioactivity by the pre-injection of blockers confirms its high specificity. Slightly reduced apical ${ }^{18}$ F-FDG uptake was observed in the left ventricle, revealing reduced myocardial viability with corresponding sympathetic nerve denervation in the heart, as indicated by ${ }^{11} \mathrm{C}-\mathrm{Me} @$ HAPTHI uptake in the ischemic region ( $\mathrm{Li}$ et al. 2016). These preliminary data have proved the feasibility of cardiac imaging using different core structures, opening a door to the development of a new series of radiotracers for the diagnosis of cardiac innervation, and reducing the effect of the subcellular conditions of the sympathetic nerve terminals. The fact of being a carbon11-labeled tracer might prevent its further application, but several ways have been proven possible for the modification of this tracer into a fluorine-18-labeled one with improved properties.

\section{${ }^{11} \mathrm{C}-\mathrm{MRB}$}

(S,S)- $\left[{ }^{11} \mathrm{C}\right] O$-methyl-reboxetine $\left({ }^{11} \mathrm{C}-\mathrm{MRB}\right)$ is the methyl analogue of reboxetine (Fig. 1b), a specific NET inhibitor and antidepressant against panic disorders and ADHD. The enantiomeric pure tracer was yielded after resolution via chiral HPLC (Lin and Ding 2004). Only (S,S)- ${ }^{11} \mathrm{C}-\mathrm{MRB}$ $\left(\mathrm{IC}_{50} 2.5 \mathrm{nM}\right.$ vs. $85 \mathrm{nM}$ of (R,R)-isomer) shows strong DMI sensitivity and high specific uptake in the NET-rich regions of the brain and heart in baboons (Ding et al. 2003). It shows higher specific binding to NET than other NET inhibitor-derived ligands, such as nisoxetine or oxaprotiline (Ding et al. 2005). In addition, ${ }^{11} \mathrm{C}-\mathrm{MRB}$ has a sixfold higher affinity for NET than SERT. Although there are conflicting results based on a baboon study concerning the sensitivity and reliability of its utility as a PET radiotracer (Severance et al. 2007), ${ }^{11} \mathrm{C}$-MRB studies in rhesus monkeys have demonstrated its suitability for the determination of NET occupancy, using dose-dependent inhibition by infusion of the NET inhibitor atomoxetine (Gallezot et al. 2011). The first human study performed involved 24 male subjects. The NET density determined by ${ }^{11} \mathrm{C}-\mathrm{MRB}$ PET in these subjects follows the order of locus coeruleus, thalamus, and caudate nucleus, which is in accordance with the results obtained from NHP (Logan et al. 2007).

Following the confirmation of its feasibility, ${ }^{11} \mathrm{C}-\mathrm{MRB}$ has been applied to monitor NET density in the CNS under pathological conditions in several different fields, including obesity, ADHD, and PD. Noradrenergic dysfunction and impaired NE clearance are implicated in obesity. Consequently, the researchers using ${ }^{11} \mathrm{C}-\mathrm{MRB}$ PET have come to mutual conclusions that the NET availability in the thalamus region of obese adults is decreased when compared to healthy controls ( $\mathrm{Li}$ et al. 2014; Bresch et al. 2017). In addition, by measuring the CNS NET availability, it is possible to predict the result of a dietary intervention, and is helpful for adjusting treatment options of highly obese adults (Vettermann et al. 2018). BAT plays a role in energy balance and is also regulated by the SNS. After an initial evaluation of ${ }^{11} \mathrm{C}-\mathrm{MRB}$ in rats, tracer uptake in $\mathrm{BAT}$, with proved specificity under basal, room temperature conditions, was observed to be threefold higher than that of ${ }^{18}$ F-FDG. However, the latter one requires cold stimulation for good imaging quality (Lin et al. 2012). The same result could be replicated in humans, showing ${ }^{11} \mathrm{C}-\mathrm{MRB}$ uptake in BAT to be equally evident under both room temperature and cold conditions, though with gender differences (Hwang et al. 2015). When ${ }^{11} \mathrm{C}$-MRB PET was further applied to monitor BAT only in healthy women, findings were consistent with reports that, as mentioned above, NET is decreased in obesity, which suggests that sympathetic innervation of BAT is altered in obesity (Sanchez-Rangel et al. 2019). ADHD is a heterogeneous disorder with NET as the key target for treatment. A PETMRI study using ${ }^{11} \mathrm{C}$-MRB has successfully demonstrated that, rather than morphological changes, there is a decrease in NET availability in fronto-parietal-thalamic-cerebellar regions in the brains of ADHD patients (Ulke et al. 2019). Cardiac ${ }^{123}$ I-MIBG scintigraphy has been proposed for early detection of $\mathrm{PD}$, but its feasibility as a routine clinical practice is limited (Skowronek et al. 2019). The potential of evaluating PD patients using ${ }^{11} \mathrm{C}$-MRB PET has been confirmed, and the imaging protocol has been optimized following the investigation of kinetic models. An acquisition time of $30 \mathrm{~min}$ after 50 or $60 \mathrm{~min}$ of tracer injection allows for a reliable estimation of NET, which can significantly reduce the discomfort of PD patients (Brumberg et al 2019). Lastly, in addition to the above applications, ${ }^{11} \mathrm{C}$-MRB has also been used to investigate noradrenergic activation and modulation in different regions of the brain in response to insulin-induced hypoglycemia (Belfort-DeAguiar et al. 2018).

\section{${ }^{18}$ F-FMeNER-D}

${ }^{18} \mathrm{~F}-\mathrm{FMeNER}-\mathrm{D}_{2}$ is a fluorine-18-labeled CNS NET tracer that is the di-deuterated analogue of ${ }^{18} \mathrm{~F}$-FMeNER, developed to improve its in vivo stability by reducing the defluorination (Fig. 1b). A preliminary study in rhesus monkeys demonstrated fast and long retention of ${ }^{18} \mathrm{~F}$-FMeNER-D ${ }_{2}$ in the thalamus and brainstem (Takano et al. 2009). It is prepared by $O$-fluoromethylation of desfluoromethoxy(S,S)-FMeNER with ${ }^{18} \mathrm{~F}$-di-deutero-bromofluoromethane. After optimization, fully automated radiolabeling can be performed, yielding 1.0-2.5 GBq of formulated tracer 
within 95 min (Rami-mark et al. 2013). It initially shows DMI-sensitive binding to NET in monkeys and in ex vivo autoradiography on post-mortem human brains. The tracers are localized in the locus coeruleus and thalamus (Schou et al. 2004; 2005). An initial in vitro investigation of the tracer revealed stability against MAO and catechol- $O$-methyl transferase (COMT), along with fast metabolism by CYP450 enzymes (Rami-Mark et al. 2016). An evaluation on the post-mortem $\mathrm{AD}$ brain tissue with autoradiography showed a significant decrease in NET densities in various brain regions (e.g. thalamus), indicating the possible use of ${ }^{18} \mathrm{~F}$-FMeNER-D 2 PET as imaging biomarker in AD (Gulyás et al. 2010).

Takano et al. (2008a, b) evaluated the tracer in healthy subjects, which showed a good radiation tolerance in the entire body, and especially good brain penetration and selective retention in NET-rich regions. A further study indicated that combining the radiotracer with a template method can map the distribution of NET in different regions of the brain. Functional regions of interest (ROIs) with higher nondisplaceable binding potential $\left(\mathrm{BP}_{\mathrm{ND}}\right)$ thresholds yielded higher $\mathrm{BP}_{\mathrm{ND}}$ and lower coefficients of variance than did anatomical ROIs (Takano et al. 2008c). The regional distribution of the tracer is highest in the thalamus and lowest in the caudate, which is in accordance with the results demonstrated by previous PET and post-mortem studies of NET on human brain tissue. This opens up the potential of noninvasive estimation of NET occupancy by antidepressants (Arakawa et al. 2008).

In recent years, with the solid potential of NET imaging in the CNS being proven, ${ }^{18} \mathrm{~F}-\mathrm{FMeNER}-\mathrm{D}_{2}$ has been used in several clinical studies focused on the quantification of NET density in ROIs, along with its changes in different related diseases. However, quantification of NET in the cerebral cortex has been difficult due to the unfavorable kinetics of ${ }^{11} \mathrm{C}-\mathrm{MRB}$ and the defluorination of ${ }^{18} \mathrm{~F}-\mathrm{FMeNER}-\mathrm{D}_{2}$, along with the disadvantages due to the short half-life of carbon11-labeld tracers. After systemic evaluation of the tracer distribution in ten healthy volunteers, Moriguchi et al. established methods for quantifying NET densities in the brain through the performance of 90-min dynamic scans, which then provided a sufficient amount of data while being unaffected by the defluorination that normally begins to increase beyond $120 \mathrm{~min}$ (Moriguchi et al. 2017a).

The NET has been suggested to play a crucial role in major depressive disorder (MDD), but its availability in this disease and its relationship with clinical symptoms are not clear. A 19-patient MDD study using ${ }^{18}$ F-FMeNER-D 2 PET revealed a positive correlation between $\mathrm{BP}_{\mathrm{ND}}$ values in the thalamus region and altered attention in the patients (Moriguchi et al. 2017b). As it binds to NET (i.e. NET targeting), ${ }^{18}$ F-FMeNER-D ${ }_{2}$ can, therefore, not only reveal the distribution and density of CNS NET but also show NET occupancy by antidepressants or antipsychotics. Presently, investigated ligands include nortriptyline (Sekine et al. 2010), clomipramine (Takano et al. 2011), quetiapine (Nyberg et al. 2013), milnacipran (Takano et al. 2013; Nogami et al. 2013), nortriptyline (Takano et al. 2014), and duloxetine (Moriguchi et al. 2017c), which compete for the transportation via NET. In all cases, the estimated administration dose, as well as plasma drug concentration, can be obtained to guide the drug application. The NET occupancy measurement may provide information regarding the spectrum of efficacy of an antidepressant. Some reported antidepressant drugs involve blockade of both SERT and NET. Using ${ }^{18}$ F-FMeNER$\mathrm{D}_{2}$ PET measurements, it has been proved that venlafaxine occupies $8-61 \%$ of NET in a dose-dependent manner, as seen in a study involving 12 major depressive disorder patients who had responded to venlafaxine (Arakawa et al. 2019a). Thus, ${ }^{18}$ F-FMeNER-D ${ }_{2}$ PET can also be used to predict the potential of certain drugs as an antidepressants, exemplified by the research on tramadol in NHP (Arakawa et al. 2019b).

In contrast to the application of ${ }^{11} \mathrm{C}-\mathrm{MRB}$ in ADHD, a study on ${ }^{18}$ F-FMeNER-D 2 PET by Vanicek et al. (2014) found no significant difference in either NET availability or distribution in ADHD-relevant regions of the brain. However, Sigurdardottir et al. (2016) used it to identify the genotype-dependent difference in NET $\mathrm{BP}_{\mathrm{ND}}$ between healthy controls and ADHD patients. It provided further evidence of NET imbalance in several brain areas, pointing to epigenetic dysfunction in ADHD (Sigurdardottir et al. 2019).

\section{${ }^{18}$ F-NS12137}

Another CNS fluorine-18-labeled tracer is exo-3-[(6- $\left[{ }^{18} \mathrm{~F}\right]$ fluoro-2-pyridyl)oxy]-8-azabicyclo[3.2.1]-octane $\left({ }^{18} \mathrm{~F}\right.$ NS12137), which is derived from ${ }^{11} \mathrm{C}-\mathrm{NS} 8880$ (Vase et al. 2014), and has shown good selectivity over SERT and DAT (Fig. 1b). It has been successfully radiolabeled using both the ${ }^{18} \mathrm{~F}-\mathrm{F}_{2}$ and ${ }^{18} \mathrm{~F}$-selectfluor methods, with radiochemical yield $3.9 \%$ and $10.2 \%$, respectively (Kirjavainen et al. 2018). The radiolabeling method was then optimized using a copper-mediated pathway and stannane precursor to obtain ${ }^{18} \mathrm{~F}-\mathrm{NS} 12137$ with $15.1 \%$ yield and up to $300 \mathrm{GBq} / \mu \mathrm{mol}$ specific activity (Lahdenpohja et al. 2019a, b). Further optimization of the fluorination using a bromide precursor led to $18.6 \%$ yield and $>500 \mathrm{GBq} / \mu \mathrm{mol}$ specific activity (LópezPicón et al. 2019). Its uptake in NET-rich areas of the rat brain was demonstrated with specificity proven by pretreatment of nisoxetine, a known NET antagonist. Defluorination and slow increase of bone uptake could be observed after time (Kirjavainen et al. 2018). PET imaging in adult and immature Sprague-Dawley rats, along with ex vivo studies using autoradiography, has demonstrated uptake of the radiotracer in brain areas rich in NET, especially the locus coeruleus, a quite small volume for PET imaging. The tracer 
shows optimal characteristics (such as fast washout and high specificity) that are favorable for NET imaging in the brain (López-Picón et al. 2019).

\section{Discussion}

\section{NET targeting and NET-function targeting tracers}

The term "NET targeting" has always been used when discussing the diagnosis of SNS in the heart, both in other reviews and in the present one. However, it is worth mentioning that all the cardiac radiotracers described above are actually "NET function targeting", because they will be taken up by NET and transported into the neurons, particularly granular vesicles, with the exception of ${ }^{11} \mathrm{C}$ HED as discussed above (Werner et al. 2015). Therefore, the PET signal reflects the transportation/density of NET, which relies on the structural integrity of the sympathetic neurons. In addition, there are also NET structure-targeting radiotracers, mostly derived from antidepressants and mainly used in the imaging of NET density in the CNS. The rationale behind this is the lipophilicity of these compounds. On the one hand, this allows them to easily pass the $\mathrm{BBB}$, on the other hand, it may lead to high liver uptake that is not ideal for cardiac imaging due to the scattering effect. As a result, there is almost a clear-cut boundary between cardiac NET tracers and CNS NET tracers: the former ones are majority NET function-targeting tracers with polar benzylguanidine or phenethylguanidine structures, whereas the latter ones are mostly derived from known NET-selective antidepressants with BBB penetration properties. Researchers have attempted to modify the chemical structure of MIBG by introducing 1,4-dihydroquinoline as chemical delivery system to improve its uptake in the brain, but the result requires further optimization (Gourand et al. 2019). The structural-functional difference is due to the different properties between the heart and the brain. Assessment of sympathetic innervation depends on both the blood flow-through which the tracer reaches the target tissue-and the NET uptake kinetics. Subsequently, most known radiotracers, such as MIBG and LMI1195, are quickly transported into the neurons and therefore cannot be used to quantify NET density precisely. The design rationale of 3F-MHPG and 4F-PHPG by researchers from University of Michigan counteracted this issue by introducing tracers with slow-uptake mechanisms, which has been proven in ex vivo rat heart studies, and in NHP (Raffel et al. 2007). Clinical trials of these tracers are still ongoing, and further proofs of the concept are needed.

\section{NET tracer specificity and selectivity}

In this review, we have provided an overview of the currently reported NET radiotracers derived from its natural substrate, NE, or NET-selective antidepressants. This has included not only their preclinical evaluation and clinical application, but also their potential use in the fields other than heart and neuroendocrine tumors. Several carbon-11 and fluorine-18-labeled tracers derived from antidepressant drugs with chemical structures different from cardiac ones have been used in the investigation of CNS imaging, in the context of ADHD and PD, for example. The advantages of using carbon-11 radioisotope are: the easy access to their corresponding precursors, along with their unchanged chemical structures and biological properties in vivo, particularly when the CNS is involved, as the development of new structures by chemists requires much longer time. In addition, the new generation of fluorine18-labeled PET tracers, such as ${ }^{18} \mathrm{~F}-\mathrm{LMI} 1195$ and ${ }^{18} \mathrm{~F}-4 \mathrm{~F}-$ MHPG/3F-PHPG, has already reached clinical trials, and demonstrated excellent imaging quality and spectacular kinetic advantages of quantifying regional innervation. Furthermore, the distinctive slow neuronal uptake and long-term neuronal retention in the heart represented by the phenethylguanidine series of NET-function targeting tracers has provided clinicians with more possibilities for quantitatively measuring regional denervation conditions. Thus, from the classical SPECT tracer ${ }^{123}$ I-MIBG, with its benzylguanidine core structure, to the latest easily labeled PET tracer, ${ }^{18} \mathrm{~F}$-AF78, more details regarding the structure-activity relationships of these NET-function targeting radiotracers have been revealed, which is helpful for the design of new generation PET tracers.

However, it should be mentioned that the currently available radiolabeled tracers or therapeutic agents are not selective to NET transport function. In the human or animal body, several extra-neuronal uptake mechanisms, or nonadrenergic uptake, such as DAT and SERT uptake, also exist and are responsible for the extraction and excretion of these radiotracers into or through different organs, which may lead to unfavorable uptake and corresponding side effects. Due to the fact that either the guanidine moiety of the MIBGderived NET-function targeting tracers or antidepressantderived NET-targeting CNS tracers would be in cation form under physiological conditions, organic cation transporters (OCTs) are considered to contribute most to these extraneuronal uptake mechanisms (Fig. 4). Among the subtypes of the OCT family, OCT1 and OCT2 are critical for the elimination of a wide array of drugs and environmental toxins and are restricted mainly to excretory organs, dominantly in the liver and kidney, respectively (Solbach et al. 2011), which may be the molecular basis of the liver or kidney uptake of radiotracers. OCT3 transports a wide range of 


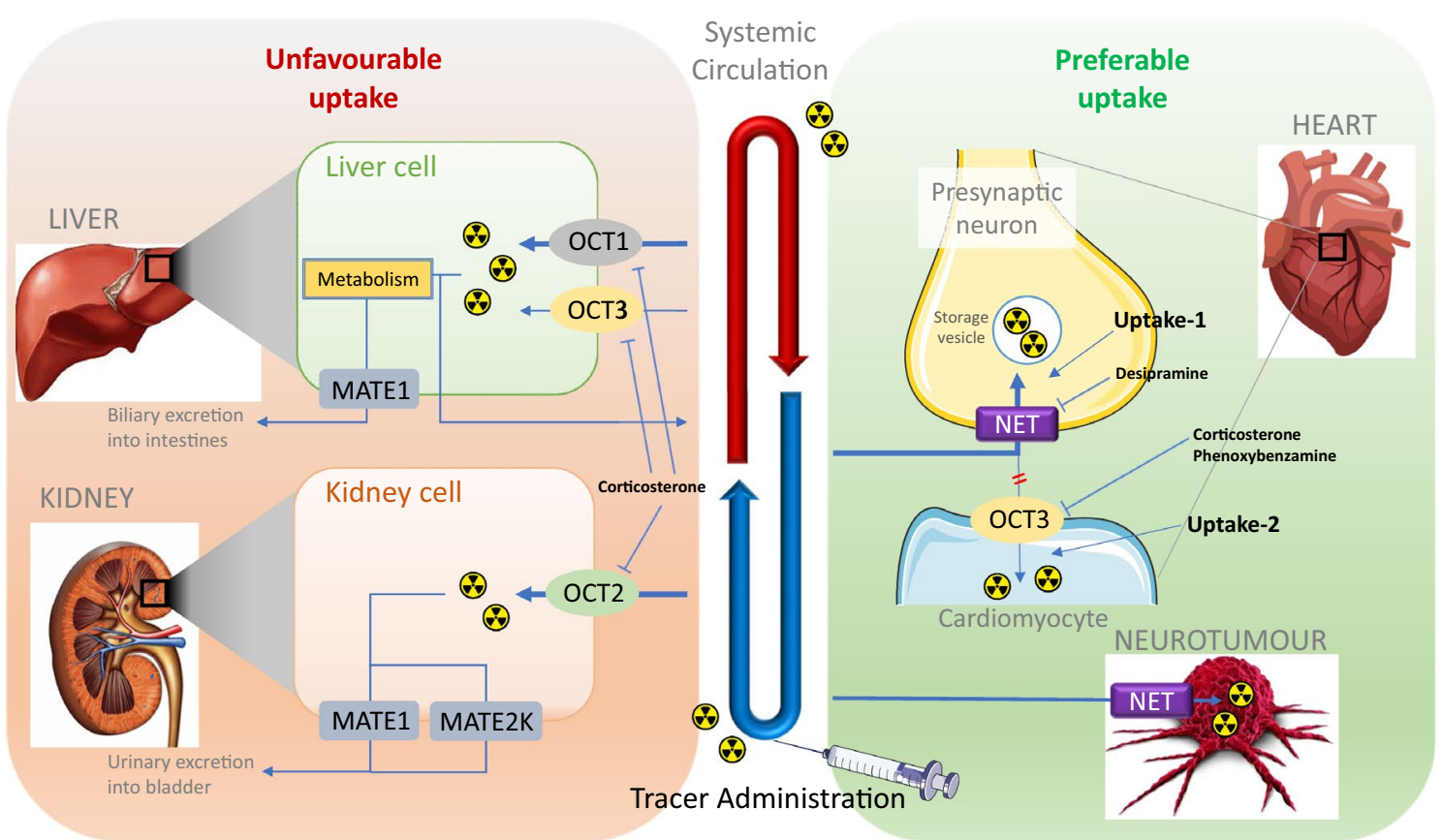

Fig. 4 Illustration of simplified NET-targeting radiotracer biodistribution. This figure was created using Microsoft PowerPoint version 15.38 for Mac then pasted as PDF format into Word file

monoamine neurotransmitters, hormones, and steroids and shows a much broader tissue distribution, including skeletal muscle, heart (Solbach et al. 2011), brain (Wu et al. 1998; Gasser and Lowry 2018), and placenta (Chen et al. 2010). Although OCT3 has a major expression in the brain, it is unlikely that the currently reviewed tracers with guanidine moieties will be able to penetrate the BBB due to their very polar guanidine structures. Such radiotracers targeting NET, yet mediated by OCT3 uptake in the CNS, would be prudently considered.

Until now, although several radiotracers targeting NET transport-function have been reported, no NET-selective compound has been reported and no such agent has been approved for clinical application. All the research focus is on either NET or OCTs alone, but without correlating the OCT-dependent side effects to improve the NET-selectivity for higher accuracy diagnosis and higher efficiency cancer therapy. As the only NET-function targeting tracer currently applied clinically, ${ }^{123 / 131}$ I-MIBG is not exclusively selective towards NET but can be also taken up by OCTs in both animal models and humans. Consequently, its uptake might not accurately reflect the SNS function of the heart or properly affect cancer therapy, which urges the development of radiotracers with higher NET selectivity over OCTs, for better imaging accuracy and therapeutic specificity. Ito et al. (2012) have already proven MIBG uptake via hOCT1 and hOCT2 in HEK295 cells. First, less NET-selective radiotracers with intensive liver uptake, presumably via
OCT1, decrease the H/L contrast and make it difficult to interpret the condition of the heart in the LV inferior wall. Photon scattering from high liver radioactivity accumulation remains a challenge for the diagnosis of heart diseases (Kim et al. 2010). Second, researches, such as ${ }^{123}$ I-MIBG imaging involving therapy-resistant hypertension patients before and after catheter-based renal sympathetic denervation or kidney autotransplantation (Dobrowolski et al. 2015, 2018), have proven the uptake of MIBG into kidney irrelevant to sympathetic nerve activity in the kidney, presumably due to its non-specific uptake via OCT2 or other transporters. Thus, a NET-selective tracer would open a new door for the diagnosis of renal sympathetic innervation. Furthermore, decreased OCT activity of NET-targeting radiotracers may reduce the fast excretion through kidneys and the rapid urinary elimination, which has always resulted in the bladder being the actual critical organ for imaging or therapy. Therefore, a higher NET selectivity might reduce the speed of excretion, which would consequently reduce the overall dose administration and the corresponding unnecessary off-target radiation exposure. Third, in addition to the specific tumor uptake required for diagnostic and therapeutic applications, non-tumorous tissues also incorporate MIBG through OCTs (Bayer et al. 2009, 2016), which will reduce the effective radiation dosage for the target organ while causing an unnecessarily high dose utilization of radioactivity and delayed toxicity in these related organs. It has been reported that with pretreatment of hydrocortisone, the liver and heart uptake of 
MIBG in patients was reduced due to the blocking of OCTs (Bayer et al. 2016). Therefore, it is conceivable that with NET-selective radiotracers and derivatives, such additional drug intervention can be prevented and the radiation dose required could be further decreased, especially when juvenile or elderly patients are involved (Agrawal et al. 2018). It is crucial to summarize the SARs of the radiotracers selectively targeting NET over OCTs using different cellular- and animal-based models, which is helpful for elucidating the role of OCTs in drug design and kinetics optimization.

A NET tracer might also be taken up by other monoamine transporters, such as DAT and SERT. Both play very minor roles in the heart as far as it is reported. However, in the $\mathrm{CNS}$, it is crucial to investigate the selectivity of radiotracers targeting CNS NET, both in cell-based assays and in animal studies. Therefore, a blocking study, i.e. a pretreatment with DMI that significantly reduces the uptake of potential NET tracers, is always performed in all in vitro and in vivo studies. DMI has been proven as a NET selective blocker with minor effects on SERT (Biaggioni and Robertson 2012; Owens et al. 1997; Tatsumi and Groshan 1997). Further study in a rabbit model confirmed that the dosage required to inhibit MIBG uptake is much higher with escitalopram than with DMI. These results proved that MIBG uptake is selective to NET over SERT (Werner et al. 2018). In an early study investigating MIBG uptake by sympathetic neurons, the human NET, bovine DAT, and the rat SERT were cloned and expressed in various cell lines. The results also demonstrated nanomolar-range inhibition of MIBG uptake by DMI, with no significant uptake by bovine DAT or rat SERT (Glowniak et al. 1993). As a result, it is reasonable to believe that these reported NET tracers are relatively selective to NET over DAT and SERT (Table 1). As discussed in the last section, most of the cardiac NET tracers are NET function targeting ones, which are stored in granular vesicles. Therefore, most of them show a VMAT2 affinity that allows them to be transported into the vesicles. It is difficult to summarize the pharmacological data of all reported NET tracers, since the in vitro and in vivo studies are normally performed in a large variety of cell lines, tissues, and animal species. Many targets were not considered while developing these tracers. Therefore, the results cannot be clearly presented using accurate numbers, such as an $\mathrm{IC}_{50}$ values. For the reader's convenience, we attempted to organize the related data of selected NET tracers into a table containing the transporters discussed in the current review (Table 1).
Among them, MIBG has received most of the attentions and has been investigated at a variety of targets relatively thoroughly over 30 years of clinical application.

\section{Limitations of the current strategy for the development of cardiac NET tracers}

Currently, there are three categories of cardiac NET tracers: (1) those derived directly from NE; (2) those derived from MIBG with a benzylguanidine core structure; (3) those with a phenethylguanidine core structure. The tracers from category 1 , exemplified by ${ }^{11} \mathrm{C}$-ephedrine and ${ }^{11} \mathrm{C}$-phenylephrine, are not metabolically stable against MAO. On the one hand, the guanidine moiety in categories 2 and 3 improves not only the stability of these tracers against MAO, but also increases the hydrophilicity that is helpful for reducing liver uptake where nonpolar structures are preferred. On the other hand, the guanidine structure, as suggested by the investigation of metformin, is the substrate for OCT1 and OC2. Thus, unfavorable uptake in the off-target tissues increases, as discussed in the last section. Furthermore, NET structure-targeting tracers derived from antidepressants are not preferable in the cardiac imaging due to their high lipophilicity and consequent high liver uptake. ${ }^{11} \mathrm{C}-\mathrm{Me} @ \mathrm{HAPTHI}$ is one of the few nonpolar tracers that shows both CNS and cardiac NET uptake ability. However, such research is still in its preliminary stages and, to form a more objective judgment, it is necessary to address the changing of the radionuclide from carbon-11 to fluorine-18, as well as properties such as organ selectivity, in vivo stability and kinetics. In addition to the abovementioned tracers, ${ }^{11} \mathrm{C}-\mathrm{HED}$, with its metaraminol structure, is a special type of NET tracers. It has an amine instead of guanidine-based structure yet is still MAO stable due to its $N$ - and $\alpha$-methyl substituents. It is suggested to be taken up via uptake-1/NET selectively, possibly with low affinity at OCT3. Nevertheless, in addition to the disadvantages stemming from carbon11-labeling, its special storage mode-constant leaking and reuptake-makes the calculation of parameters reflecting integrity of NE turnover difficult. In summary, there are still areas for improvement in designing an optimal NET tracer with NET specificity and ideal in vivo kinetics. A thorough investigation on the ligands and radiotracers targeting NET will provide useful information as well as a paradigm for obtaining highly selective NET-targeting theranostic ligands with selectivity over other transporters, especially OCTs. 


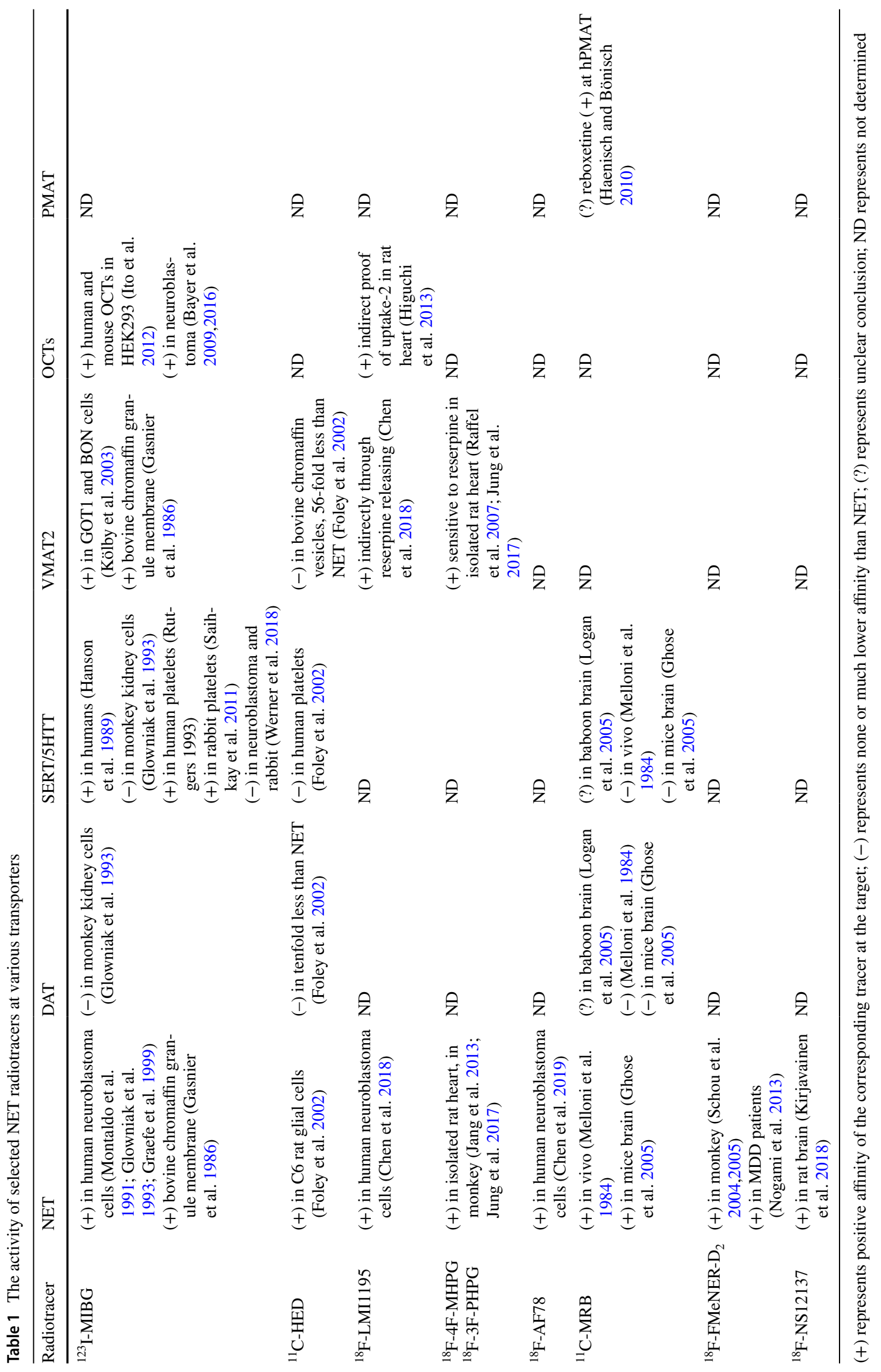


Acknowledgements This publication was supported by the Open Access Publication Fund of the University of Würzburg provided by Projekt DEAL. The authors would like to show great appreciation to Miss Milena Mihovilovic for her kind help and intensive work on clear writing and good language.

Author contributions $\mathrm{TH}$ and $\mathrm{AB}$ proposed the first idea of the review article. XC and TK have performed the literature search and drafted the article. CL critically revised and improved the quality of the work.

\section{Compliance with ethical standards}

Conflict of interest The authors declare that they have no conflict of interest.

Open Access This article is licensed under a Creative Commons Attribution 4.0 International License, which permits use, sharing, adaptation, distribution and reproduction in any medium or format, as long as you give appropriate credit to the original author(s) and the source, provide a link to the Creative Commons licence, and indicate if changes were made. The images or other third party material in this article are included in the article's Creative Commons licence, unless indicated otherwise in a credit line to the material. If material is not included in the article's Creative Commons licence and your intended use is not permitted by statutory regulation or exceeds the permitted use, you will need to obtain permission directly from the copyright holder. To view a copy of this licence, visit http://creativecommons.org/licenses/by/4.0/.

\section{References}

Agrawal A, Rangarajan V, Shah S, Puranik A, Purandare N (2018) MIBG (metaiodobenzylguanidine) theranostics in pediatric and adult malignancies. Br J Radiol 91(1091):20180103

Aikawa T, Naya M, Obara M, Oyama-Manabe N, Manabe O, Magota $\mathrm{K}$ et al (2017) Regional interaction between myocardial sympathetic denervation, contractile dysfunction, and fibrosis in heart failure with preserved ejection fraction: 11C-hydroxyephedrine PET study. Eur J Nucl Med Mol Imaging 44(11):1897-1905

Arakawa R, Okumura M, Ito H, Seki C, Takahashi H, Takano H et al (2008) Quantitative analysis of norepinephrine transporter in the human brain using PET with (S, S)-18F-FMeNER-D2. J Nucl Med 49(8):1270-1276

Arakawa R, Stenkrona P, Takano A, Svensson J, Andersson M, Nag S et al (2019a) Venlafaxine ER blocks the norepinephrine transporter in the brain of patients with major depressive disorder: a PET study using [18F]FMeNER-D2. Int J Neuropsychopharmacol 22(4):278-285

Arakawa R, Takano A, Halldin C (2019b) Serotonin and norepinephrine transporter occupancy of tramadol in nonhuman primate using positron emission tomography. Int J Neuropsycholpharmacol 22(1):53-56

Bayer M, Kuçi Z, Schömig E, Gründemann D, Dittmann H, Handgretinger R, Bruchelt G (2009) Uptake of mIBG and catecholamines in noradrenaline- and organic cation transporter-expressing cells: potential use of corticosterone for a preferred uptake in neuroblastoma- and pheochromocytoma cells. Nucl Med Biol 36(3):287-294

Bayer M, Schmitt J, Dittmann H, Handgretinger R, Bruchelt G, Sauter AW (2016) Improved selectivity of mIBG uptake into neuroblastoma cells in vitro and in vivo by inhibition of organic cation transporter 3 uptake using clinically approved corticosteroids. Nucl Med Biol 43(9):543-551

Belfort-DeAguiar R, Gallezot JD, Hwang JJ, Elshafie A, Yeckel CW, Chan O, Carson RE, Ding YS, Sherwin RS (2018) Noradrenergic activity in the human brain: a mechanism supporting the defense against hypoglycemia. J Clin Endocrinol Metab 103(6):2244-2252

Biaggioni I, Robertson D (2012) Adrenoceptor agonists \& sympathomimetic drugs (Chapter 9). In: Katzung B, Masters SB, Trevor AJ (eds) Basic and clinical pharmacology. McGraw-Hill, New York

Bönisch H, Brüss M (2006) The norepinephrine transporter in physiology and disease. Handb Exp Pharmacol 175:485-524

Borodovitsyna O, Flamini M, Chandler D (2017) Noradrenergic modulation of cognition in health and disease. Neural Plast 2017:6031478. https://doi.org/10.1155/2017/6031478

Bresch A, Rullmann M, Luthardt J, Becker GA, Reissig G, Patt M et al (2017) Emotional eating and in vivo norepinephrine transporter availability in obesity: a [11C]MRB PET pilot study. Int J Eat Disord 50(2):152-156

Brumberg J, Tran-Gia J, Lapa C, Isaias IU, Samnick S (2019) PET imaging of noradrenaline transporters in Parkinson's disease: focus on scan time. Ann Nucl Med 33(2):69-77

Chen L, Pawlikowski B, Schlessinger A, More SS, Stryke D, Johns SJ et al (2010) Role of organic cation transporter 3 (SLC22A3) and its missense variants in the pharmacologic action of metformin. Pharmacognenet Genomics 20(11):687-699

Chen X, Fritz A, Werner RA, Nose N, Yagi Y, Kimura H, Rowe SP, Koshino K, Decker M, Higuchi T (2019) Initial evaluation of AF78: a rationally designed fluorine-18-Labelled PET radiotracer targeting norepinephrine transporter. Mol Imaging Biol. https://doi.org/10.1007/s11307-019-01407-5

Chen X, Werner RA, Lapa C, Hirano M, Javadi MS, Robinson S, Higuchi T (2018) Subcellular storage and release mode of the novel 18F-labeled sympathetic nerve PET tracer LMI1195. EJNMMI Res 8:12

Deep P, Gjedde A, Cumming P (1997) On the accuracy of an [18F] FDOPA compartmental model: evidence for vesicular storage of [18F]fluorodopamine in vivo. J Neurosci Methods 76(2):157-165

Delaville C, De Deurwaerdère P, Benazzouz A (2011) Noradrenaline and Parkinson's disease. Front Syst Neurosci 5:31

Ding YS, Fowler JS, Dewey SL, Logan J, Schlyer DJ, Gatley SJ, Volkow ND, King PT, Wolf AP (1993) Comparison of high specific activity (-) and (+)-6-[18F]fluoronorepinephrine and $6-[18 \mathrm{~F}]$ fluorodopamine in baboons: heart uptake, metabolism and the effect of desipramine. J Nucl Med 34(4):619-629

Ding YS, Lin KS, Garza V, Carter P, Alexoff D, Logan J, Shea C, Xu Y, King P (2003) Evaluation of a new norepinephrine transporter PET ligand in baboons, both in brain and peripheral organs. Synapse 50(4):345-352

Ding YS, Lin KS, Logan J, Benveniste H, Carter P (2005) Comparative evaluation of positron emission tomography radiotracers for imaging the norepinephrine transporter: $(\mathrm{S}, \mathrm{S})$ and $(\mathrm{R}, \mathrm{R})$ enantiomers of reboxetine analogs ([11C]methylreboxetine, 3-Cl-[11C] methylreboxetine and [18F]fluororeboxetine), (R)-[11C]nisoxetine, [11C]oxaprotiline and [11C]lortalamine. J Neurochem 94(2):337-351

Dobrowolski LC, Eeftinck Schattenkerk DW, Idu MM, van den Born BJ, Verberne HJ (2015) Renal 123I-MIBG scintigraphy before and after kidney autotransplantation. Clin Nulc Med 40(10):810-811

Dobrowolski LC, Eeftinck Schattenkerk DW, Krediet CTP, Van Brussel PM, Vogt L, Bemelman FJ, Reekers JA, Van Den Born BH, Verberne HJ (2018) Renal sympathetic nerve activity after catheter-based renal denervation. EJNMMI Res 8(1):8. https://doi. org/10.1186/s13550-018-0360-1 
Eskola O, Grönroos TJ, Naum A, Marjamäki P, Forsback S, Bergman J et al (2012) Novel electrophilic synthesis of 6-[18F]fluorodopamine and comprehensive biological evaluation. Eur J Nucl Med Mol Imaging 39(5):800-810

Fallavollita JA, Heavey BM, Luisi AJ Jr, Michalek SM, Baldwa S, Mashtare TL Jr et al (2014) Regional myocardial sympathetic denervation predicts the risk of sudden cardiac arrest in ischemic cardiomyopathy. J Am Coll Cardiol 63:141-149

Foley KF, Van Dort ME, Sievert MK, Ruoho AE, Cozzi NV (2002) Stereospecific inhibition of monoamine uptake transporters by meta-hydroxyephedrine isomers. J Neural Transm (Vienna) 109(10):1229-1240

Frantellizzi V, Ricci M, Farcomeni A, Pontico M, Pani A, Vincentis G (2020) Usefulness of 5 minutes 123I-mIBG scan in Parkinson's disease and heart failure. Curr Radiopharm. https://doi. org/10.2174/1874471013666200127122033

Fujita W, Matsunari I, Aoki H, Nekolla SG, Kajinami K (2016) Prediction of all-cause death using (11)C-hydroxyephedrine positron emission tomography in Japanese patients with left ventricular dysfunction. Ann Nucl Med 30(7):461-467

Gaertner FC, Wiedemann T, Yousefi BH, Lee M, Repokis I, Higuchi $T$ et al (2013) Preclinical evaluation of 18F-LMI1195 for in vivo imaging of pheochromocytoma in the MENX tumor model. J Nucl Med 54(12):2111-2117

Gallezot JD, Weinzimmer D, Nabulsi N, Lin SF, Fowles K, Sandiego C et al (2011) Evaluation of [(11)C]MRB for assessment of occupancy of norepinephrine transporters: Studies with atomoxetine in non-human primates. Neuroimage 56(1):268-279

Garg PK, Garg S, Zalutsky MR (1994) Synthesis and preliminary evaluation of para- and meta-[18F]fluorobenzylguanidine. Nulc Med Biol 21(1):97-103

Gasnier B, Roisin MP, Scherman D, Coornaert S, Desplanches G, Henry JP (1986) Uptake of meta-iodobenzylguanidine by bovine chromaffin granule membranes. Mol Pharmacol 29(3):275-280

Gasser PJ, Lowry CA (2018) Organic cation transporter 3: a cellular mechanism underlying rapid, non-genomic glucocorticoid regulation of monoaminergic neurotransmission, physiology, and behavior. Horm Behav 104:173-182

Ghose S, Fujita M, Morrison P, Uhl G, Murphy DL, Mozley PD, Schou M, Halldin C, Innis R (2005) Specific in vitro binding of $(\mathrm{S}, \mathrm{S})-[3 \mathrm{H}] \mathrm{MeNER}$ to norepinephrine transporters. Synapse 56(2):100-104

Glowniak JV, Kilty JE, Amara SG, Hoffman BJ, Turner FE (1993) Evaluation of metaiodobenzylguanidine uptake by the norepinephrine, dopamine and serotonin transporters. J Nucl Med 34(7):1140-1146

Goldstein DS, Chang PC, Smith CB, Herscovitch P, Austin SM, Eisenhofer G, Kopin IJ (1991) Dosimetric estimates for clinical positron emission tomographic scanning after injection of [18F]-6-fluorodopamine. J Nucl Med 32(1):102-110

Goldstein DS, Coronado L, Kopin IJ (1994) 6-[Fluorine-18]fluorodopamine pharmacokinetics and dosimetry in humans. J Nucl Med 35(6):964-973

Goldstein DS, Eisenhofer G, Dunn BB, Armando I, Lenders J, Grossman E et al (1993) Positron emission tomographic imaging of cardiac sympathetic innervation using 6-[18F]fluorodopamine: initial findings in humans. J Am Coll Cardiol 22(7):1961-1971

Goldstein DS, Eldadah B, Sharabi Y, Axelrod FB (2008) Cardiac sympathetic hypo-innervation in familial dysautonomia. Clin Auton Res 18(3):115-119

Goldstein DS, Holmes C, Lopez GJ, Wu T, Sharabi Y (2018) Cardiac sympathetic denervation predicts $\mathrm{PD}$ in at-risk individuals. Parkinsonism Relat Disord 52:90-93

Goldstein DS, Holmes C, Stuhlmuller JE, Lenders JW, Kopin IJ (1997) 6-[18F]fluorodopamine positron emission tomographic scanning in the assessment of cardiac sympathoneural function-studies in normal humans. Clin Auton Res 7(1):17-29

Goldstein DS, Katzper M, Linares O, Kopin IJ (2002) Kinetic model for the fate of 6-[18F]fluorodopamine in the human heart: a novel means to examine cardiac sympathetic neuronal function. Naunyn Schmiedebergs Arch Pharmacol 365(1):38-49

Gourand F, Patin D, Henry A, Ibazizène M, Dhilly M, Fillesoye F et al (2019) Chemical delivery system of MIBG to the central nervous system: synthesis, 11C-radiosynthesis, and in vivo evaluation. ACS Med Chem Lett 10(3):352-357

Gourgiotis L, Sarlis NJ, Reynolds JC, VanWaes C, Merino MJ, Pacak K (2003) Localization of medullary thyroid carcinoma metastasis in a multiple endocrine neoplasia type $2 \mathrm{~A}$ patient by $6-[18 \mathrm{~F}]$-fluorodopamine positron emission tomography. $\mathrm{J}$ Clin Endocrinol Metab 88(2):637-641

Graefe KH, Bossle F, Wölfel R, Burger A, Souladaki M, Bier D, Dutschka K, Farahati J, Bönisch H (1999) Sympathomimetic effects of MIBG: comparison with tyramine. J Nucl Med 40(8):1342-1351

Gulyás B, Brockschnieder D, Nag S, Pavlova E, Kása P, Beliczai Z et al (2010) The norepinephrine transporter (NET) radioligand (S, S)-[18F]FMeNER-D2 shows significant decreases in NET density in the human brain in Alzheimer's disease: a post-mortem autoradiographic study. Neurochem Int 56(6-7):789-798

Haenisch B, Bönisch H (2010) Interaction of the human plasma membrane monoamine transporter (hPMAT) with antidepressants and antipsychotics. Naunyn Schmiedebergs Arch Pharmacol 381(1):33-39

Hanson MW, Feldman JM, Blinder RA, Moore JO, Coleman RE (1989) Carcinoid tumors: iodine-131 MIBG scintigraphy. Radiol 172(3):699-703

Higuchi T, Yousefi BH, Kaiser F, Gärtner F, Rischpler C, Reder $S$ et al (2013) Assessment of the 18F-labeled PET tracer LMI1 195 for imaging norepinephrine handling in rat hearts. J Nucl Med 54(7):1142-1146

Higuchi T, Yousefi BH, Reder S, Beschorner M, Laitinen I, Yu M et al (2015) Myocardial kinetics of a novel [(18)F]-labeled sympathetic nerve PET tracer LMI1195 in the isolated perfused rabbit heart. JACC Cardiolvasc Imaging 8(10):1229-1231

Hiroshima Y, Manabe O, Naya M, Tomiyama Y, Magota K, Obara $M$ et al (2017) Quantification of myocardial blood flow with 11C-hydroxyephedrine dynamic PET: comparison with 15OH2O PET. J Nucl Cardiol 2017:1-8. https://doi.org/10.1007/ s12350-017-1140-4

Hu B, Vāvere AL, Neumann KD, Shulkin BL, DiMagno SG, Snyder SE (2015) A practical, automated synthesis of meta-[18F] fluorobenzylguanidine for clinical use. ACS Chem Neurosci 6(11):1870-1879

Hwang JJ, Yeckel CW, Gallezot JD, Aguiar RB, Ersahin D, Gao H et al (2015) Imaging human brown adipose tissue under room temperature conditions with (11)C-MRB, a selective norepinephrine transporter PET ligand. Metabolism 64:747-755

Ilias I, Chen CC, Carrasquillo JA, Whatley M, Ling A, Lazúrová I et al (2008) Comparison of 6-18F-fluorodopamine PET with 123I-metaiodobenzylguanidine and 111 in-pentetreotide scintigraphy in localization of nonmetastatic and metastatic pheochromocytoma. J Nucl Med 49(10):1613-1619

Ilias I, Yu J, Carrasquillo JA, Chen CC, Eisenhofer G, Whatley M, McElroy B, Pacak K (2003) Superiority of 6-[18F]-fluorodopamine positron emission tomography versus [131I]-metaiodobenzylguanidine scintigraphy in the localization of metastatic pheochromocytoma. J Clin Endocrinol Metab 88(9):4083-4087

Inaki A, Yoshimura K, Murayama T, Imai Y, Kuribayashi Y, Higuchi T, Jinguji M, Shiga T, Kinuya S (2017) A phase I clinical trial for [131I]meta-iodobenzylguanidine therapy in patients with 
refractory pheochromocytoma and paraganglioma: a study protocol. J Med Invest 64(34):205-209

Ito S, Kusuhara H, Yokochi M, Toyoshima J, Inoue K, Yuasa H, Sugiyama Y (2012) Competitive inhibition of the luminal efflux by multidrug and toxin extrusions, but not basolateral uptake by organic cation transporter 2 , is the likely mechanism underlying the pharmacokinetic drug-drug interactions caused by cimetidine in the kidney. J Pharmacol Exp Ther 340(2):393-403

Jang KS, Jung YW, Gu G, Koeppe RA, Sherman PS, Quesada CA, Raffel DM (2013a) 4-[18F]Fluoro-m-hydroxyphenethylguanidine: a radiopharmaceutical for quantifying regional cardiac sympathetic nerve density with positron emission tomography. J Med Chem 56(18):7312-7323

Jang KS, Jung YW, Sherman PS, Quesada CA, Gu G, Raffel DM (2013b) Synthesis and bioevaluation of [(18)F]4-fluoro-mhydroxyphenethylguanidine ([(18)F]4F-MHPG): a novel radiotracer for quantitative PET studies of cardiac sympathetic innervation. Bioorg Med Chem Lett 23(6):1612-1616

Jung YW, Gu G, Raffel DM (2019) Improved synthesis of 4-[18F] fluoro-m-hydroxyphenethylguanidine using an iodonium ylide precursor. J Labelled Comp Radiopharm 62:835-842

Jung YW, Jang KS, Gu G, Koeppe RA, Sherman PS, Quesada CA, Raffel DM (2017) [18F]Fluoro-hydroxyphenethylguanidines: efficient synthesis and comparison of two structural isomers as radiotracers of cardiac sympathetic innervation. ACS Chem Neurosci 8:1530-1542

Kaji P, Carrasquillo JA, Linehan WM, Chen CC, Eisenhofer G, Pinto PA, Lai EW, Pacak K (2007) The role of 6-[18F]fluorodopamine positron emission tomography in the localization of adrenal pheochromocytoma associated with von Hippel-Lindau syndrome. Eur J Endocrinol 156(4):483-487

Kawazoe M, Arima H, Maeda T, Tsuji M, Mishima T, Fujioka S, Tsugawa J, Tsuboi Y (2019) Sensitivity and specificity of cardiac 123I-MIBG scintigraphy for diagnosis of early-phase Parkinson's disease. J Neurol Sci 407:116409

Kim YS, Wang F, Liu S (2010) Minimizing liver uptake of cationic Tc radiotracers with ether and crown ether functional groups. World J Hepatol 2(1):21-31

King KS, Chen CC, Alexopoulos DK, Whatley MA, Reynolds JC, Patronas $\mathrm{N}$ et al (2011) Functional imaging of SDHx-related head and neck paragangliomas: comparison of $18 \mathrm{~F}$-fluorodihydroxyphenylalanine, $18 \mathrm{~F}$-fluorodopamine, $18 \mathrm{~F}$-fluoro-2-deoxyD-glucose PET, 123I-metaiodobenzylguanidine scintigraphy, and 111In-pentetreotide scintigraphy. J Clin Endocrinol Metab 96(9):2779-2785

Kirjavainen AK, Forsback S, López-Picón FR, Marjamäki P, Takkinen J, Haaparanta-Solin M, Peters D, Solin O (2018) 18F-labeled norepinephrine transporter tracer [18F]NS12137: radiosynthesis and preclinical evaluation. Nucl Med Biol 56:39-46

Kobayashi R, Chen X, Werner RA, Lapa C, Javadi MS, Higuchi T (2017) New horizon in cardiac innervation imaging: introduction of novel 18F-labeled PET tracers. Eur J Nucl Med Mol Imaging 44:2302-2309

Kölby L, Bernhardt P, Levin-Jakobsen AM, Johanson V, Wängberg B, Ahlman H, Forssell-Aronsson E, Nilsson O (2003) Uptake of meta-iodobenzylguanidine in neuroendocrine tumours is mediated by vesicular monoamine transporters. $\mathrm{Br} \mathrm{J}$ Cancer 89(7):1383-1388

Kuchar M, Mamat C (2015) Methods to increase the metabolic stability of 18F-radiotracers. Molecules 20:16186-16220

Lahdenpohja S, Keller T, Rajander J, Kirjavainen AK (2019a) Radiosynthesis of the norepinephrine transporter tracer [18F]NS12137 via copper-mediated 18 F-labelling. J Labelled Comp Radiopharm 62(6):259-264
Lahdenpohja SO, Rajala NA, Rajander J, Kirjavainen AK (2019b) Fast and efficient copper-mediated 18F-fluorination of arylstannanes, aryl boronic acids, and aryl boronic esters without azeotropic drying. EJNMMI Radiopharm Chem 4(1):28

Li CS, Potenza MN, Lee DE, Planeta B, Gallezot JD, Labaree D et al (2014) Decreased norepinephrine transporter availability in obesity: positron emission tomography imaging with $(\mathrm{S}, \mathrm{S})-[(11) \mathrm{C}]$ O-methylreboxetine. Neuroimage 86:306-310

Li ST, Holmes C, Kopin IJ, Goldstein DS (2003a) Aging-related changes in cardiac sympathetic function in humans, assessed by 6-18F-fluorodopamine PET scanning. J Nucl Med 44:1599-1603

Li ST, Tack CJ, Fananapazir L, Goldstein DS (2000) Myocardial perfusion and sympathetic innervation in patients with hypertrophic cardiomyopathy. J Am Coll Cardiol 35(7):1867-1873

Li X, Dumanic M, Rami-Mark C, Philippe C, Berroterán-Infante N, Wadsak W et al (2016) Molecular characterization of cardiac sympathetic denervation and innervation after ischemia-reperfusion injury as assessed by a novel norepinephrine transporter PET tracer [11C]Me@ HAPTHI. J Nucl Med 57(Suppl 2): 1638

Lin KS, Ding YS (2004) Synthesis, enantiomeric resolution, and selective C-11 methylation of a highly selective radioligand for imaging the norepinephrine transporter with positron emission tomography. Chirality 16(7):475-481

Lin SF, Fan X, Yeckel CW, Weinzimmer D, Mulnix T, Gallezot JD, Carson RE, Sherwin RS, Ding YS (2012) Ex vivo and in vivo evaluation of the norepinephrine transporter ligand [11C]MRB for brown adipose tissue imaging. Nucl Med Biol 39(7):1081-1086

Logan J, Ding YS, Lin KS, Pareto D, Fowler J, Biegon A (2005) Modeling and analysis of PET studies with norepinephrine transporter ligands: the search for a reference region. Nucl Med Biol 32(5):531-542

Logan J, Wang GJ, Telang F, Fowler JS, Alexoff D, Zabroski J et al (2007) Imaging the norepinephrine transporter in humans with (S, S)-[11C]O-methyl reboxetine and PET: problems and progress. Nucl Med Biol 34(6):667-679

López-Picón FR, Kirjavainen AK, Forsback S, Takkinen JS, Peters D, Haaparanta-Solin M, Solin O (2019) In vivo characterization of a novel norepinephrine transporter PET tracer [18F] NS12137 in adult and immature Sprague-Dawley rats. Theranostics 9(1):11-19

Mamede M, Carrasquillo JA, Chen CC, Del Corral P, Whatley M, Ilias I, Ayala A, Pacak K (2006) Discordant localization of 2-[18F]fluoro-2-deoxy-D-glucose in 6-[18F]-fluorodopamine- and [(123) I]-metaiodobenzylguanidine-negative metastatic pheochromocytoma sites. Nucl Med Commun 27(1):31-36

Mangner TJ, Tobes MC, Wieland DW, Sisson JC, Shapiro B (1986) Metabolism of iodine-131 metaiodobenzylguanidine in patients with metastatic pheochromocytoma. J Nucl Med 27(1):37-44

Mark C, Bornatowicz B, Mitterhauser M, Hendl M, Nics L, Haeusler $D$ et al (2013) Development and automation of a novel NET-PET tracer: [11C]Me@APPI. Nucl Med Biol 40(2):295-303

Melloni P, Carniel G, Della Torre A, Bonsignori A, Buonamici M, Pozzi O et al (1984) Potential antidepressant agents. a-aryloxybenzyl derivatives of ethanolamine and morpholine. Eur J Med Chem 19:235-242

Montaldo PG, Lanciotti M, Casalaro A, Cornaglia-Ferraris P, Ponzoni M (1991) Accumulation of m-iodobenzylguanidine by neuroblastoma cells results from independent uptake and storage mechanisms. Cancer Res 51(16):4342-4346

Moriguchi S, Kimura Y, Ichise M, Arakawa R, Takano H, Seki C et al (2017a) PET Quantification of the norepinephrine transporter in human brain with (S, S)-18F-FMeNER-D2. J Nucl Med 58(7):1140-1145 
Moriguchi S, Takano H, Kimura Y, Nagashima T, Takahata K, Kubota $M$ et al (2017b) Occupancy of norepinephrine transporter by duloxetine in human brains measured by positron emission tomography with (S, S)-[18F]FMeNER-D2. Int J Neuropsychopharmacol 20(12):957-962

Moriguchi S, Yamada M, Takano H, Nagashima T, Takahata K, Yokokawa K et al (2017c) Norepinephrine transporter in major depressive disorder: A PET study. Am J Psychiatry 174(1):36-41

Muzik O, Mangner TJ, Leonard WR, Kumar A, Granneman JG (2017) Sympathetic innervation of cold-activated brown and white fat in lean young adults. J Nucl Med 58(5):799-806

Niimi Y, Ito S, Murate K, Hirota S, Hikichi C, Ishikawa T et al (2017) Usefulness of combining 123I-FP-CIT-SPECT striatal asymmetry index and cardiac 123I-metaiodobenzylguanidine scintigraphy examinations for diagnosis of parkinsonisms. J Neurol Sci 377:174-178

Nogami T, Takano H, Arakawa R, Ichimiya T, Fujiwara H, Kimura Y et al (2013) Occupancy of serotonin and norepinephrine transporter by milnacipran in patients with major depressive disorder: a positron emission tomography study with [(11)C]DASB and (S, S)-[(18)F]FMeNER-D(2). Int J Neuropsychopharmacol 16(5):937-943

Nuvoli S, Palumbo B, Malaspina S, Madeddu G, Spanu A (2018) 123I-ioflupane SPET and 123I-MIBG in the diagnosis of Parkinson's disease and parkinsonian disorders and in the differential diagnosis between Alzheimer's and Lewy's bodies dementias. Hell J Nucl Med 21(1):60-68

Nyberg S, Jucaite A, Takano A, Kågedal M, Cselényi Z, Halldin C, Farde L (2013) Norepinephrine transporter occupancy in the human brain after oral administration of quetiapine XR. Int $\mathbf{J}$ Neuropsychopharmacol 16(10):2235-2244

Okada Y, Shiraishi M, Nakamura H, Maki F, Sasaki N, Hasegawa Y, Sasaki O, Nakashima Y (2018) Usefulness of the combination of iodine-123-metaiodobenzylguanidine scintigraphy and iodine123-ioflupane scintigraphy in new-onset Parkinson's disease. Nucl Med Commun 39(11):983-988

Owens MJ, Morgan WN et al (1997) Neurotransmitter receptor and transporter binding profile of antidepressants and their metabolites. J Pharmacol Exp Ther 283(3):1305-1322

Pacak K, Eisenhofer G, Carrasquillo JA, Chen CC, Li ST, Goldstein DS (2001) 6-[18F]fluorodopamine positron emission tomographic (PET) scanning for diagnostic localization of pheochromocytoma. Hypertension 38(1):6-8

Pandit-Taskar N, Modak S (2017) Norepinephrine Transporter as a Target for Imaging and Therapy. J Nucl Med 58(Suppl 2):39S-53S

Pandit-Taskar N, Zanzonico P, Staton KD et al (2018) Biodistribution and dosimetry of 18F-meta-fluorobenzylguanidine: a first-inhuman PET/CT imaging study of patients with neuroendocrine malignancies. J Nucl Med 59(1):147-153

Pfluger T, Piccardo A (2017) Neuroblastoma: MIBG imaging and new tracers. Semin Nucl Med 47(2):143-157

Pietilä M, Malminiemi K, Ukkonen H, Saraste M, Någren K, Lehikoinen P et al (2001) Reduced myocardial carbon-11 hydroxyephedrine retention is associated with poor prognosis in chronic heart failure. Eur J Nucl Med 28:373-376

Pryma DA, Chin BB, Noto RB, Dillon JS, Perkins S, Solnes L et al (2019) Efficacy and Safety of High-Specific-Activity 131I-MIBG Therapy in Patients with Advanced Pheochromocytoma or Paraganglioma. J Nucl Med 60(5):623-630

Purohit A, Harris TD, Radeke HS, Robinson SP, Yu M, Casebier DS (2008) Ligands for imaging cardiac innervation. Patent WO/2008/083056

Raffel DM, Chen W, Jung YW, Jang KS, Gu G, Cozzi NV (2013a) Radiotracers for cardiac sympathetic innervation: transport kinetics and binding affinities for the human norepinephrine transporter. Nucl Med Biol 40(3):331-337
Raffel DM, Crawford T, Jung YW, Koeppe R, Gu G, Rothley J, Frey K (2017) Quantifying cardiac sympathetic nerve density using 18F-hydroxyphenethylguanidines: pilot studies in heart failure patients staged for implantable cardioverter defibrillator placement. J Nucl Med 58(Suppl 1):96

Raffel DM, Jung YW, Gildersleeve DL, Sherman PS, Moskwa JJ, Tluczek LJ, Chen W (2007) Radiolabeled phenethylguanidines: novel imaging agents for cardiac sympathetic neurons and adrenergic tumors. J Med Chem 50(9):2078-2088

Raffel DM, Jung YW, Koeppe RA, Jang KS, Gu G, Scott PJH, Murthy VL, Rothley J, Frey KA (2018) First-in-human studies of [18F] fluorohydroxyphenethylguanidines. Circ Cardiovasc Imaging 11:e007965

Raffel DM, Koeppe RA, Jung YW, Gu G, Jang KS, Sherman PS, Quesada CA (2013b) Quantification of cardiac sympathetic nerve density with $\mathrm{N}-11 \mathrm{C}$-guanyl-meta-octopamine and tracer kinetic analysis. J Nucl Med 54(9):1645-1652

Rami-Mark C, Berroterán-Infante N, Philippe C, Foltin S, Vraka C, Hoepping A et al (2015) Radiosynthesis and first preclinical evaluation of the novel norepinephrine transporter pet-ligand [(11)C]ME@HAPTHI. EJNMMI Res 5(1):113

Rami-Mark C, Eberherr N, Berroterán-Infante N, Vanicek T, Nics L, Lanzenberger R et al (2016) [(18)F]FMeNER-D2: a systematic in vitro analysis of radio-metabolism. Nucl Med Biol 43(8):490-495

Rami-Mark C, Zhang MR, Mitterhauser M, Lanzenberger R, Hacker M, Wadsak W (2013) [18F]FMeNER-D2: reliable fully-automated synthesis for visualization of the norepinephrine transporter. Nucl Med Biol 40(8):1049-1054

Rischpler C, Fukushima K, Isoda T, Javadi MS, Dannals RF, Abraham R, Wahl R, Bengel FM, Higuchi T (2013) Discrepant uptake of the radiolabeled norepinephrine analogues hydroxyephedrine (HED) and metaiodobenzylguanidine (MIBG) in rat hearts. Eur J Nucl Med Mol Imaging 40(7):1077-1083

Saihkay HN, Rickards KJ, Page CP, Ballinger JR (2011) Validating 123I-metaiodobenzylguanidine as a platelet marker for noninvasive imaging in rabbits. J Pharmacol Toxicol Methods 63(1):69-78

Sanchez-Rangel E, Gallezot JD, Yeckel CW, Lam W, Belfort-DeAguiar R, Chen MK, Carson RE, Sherwin R, Hwang JJ (2019) Norepinephrine transporter availability in brown fat is reduced in obesity: a human PET study with [11C] MRB. Int J Obes (Lond). https://doi.org/10.1038/s41366-019-0471-4

Schou M, Halldin C, Pike VW, Mozley PD, Dobson D et al (2005) Post-mortem human brain autoradiography of the norepinephrine transporter using (S, S)-[18F]FMeNER-D2. Eur Neuropsychopharmacol 15(5):517-520

Schou M, Halldin C, Sóvágó J, Pike VW, Hall H, Gulyás B et al (2004) PET evaluation of novel radiofluorinated reboxetine analogs as norepinephrine transporter probes in the monkey brain. Synapse 53(2):57-67

Schroeder C, Jordan J (2012) Norepinephrine transporter function and human cardiovascular disease. Am J Physiol Heart Circ Physiol 303(11):H1273-H1282

Sekine M, Arakawa R, Ito H, Okumura M, Sasaki T, Takahashi H et al (2010) Norepinephrine transporter occupancy by antidepressant in human brain using positron emission tomography with (S, S)-[18F]FMeNER-D2. Psychopharmacology 210(3):331-336

Severance AJ, Milak MS, Kumar JSD, Prabhakaran J, Majo VJ, Simpson NR et al (2007) In vivo assessment of [11C]MRB as a prospective PET ligand for imaging the norepinephrine transporter. Eur J Nucl Med Mol Imaging 34(5):688-693

Sigurdardottir HL, Kranz GS, Rami-Mark C, James GM, Vanicek T, Gryglewski $\mathrm{G}$ et al (2016) Effects of norepinephrine transporter 
gene variants on NET binding in ADHD and healthy controls investigated by PET. Hum Brain Mapp 37(3):884-895

Sigurdardottir HL, Kranz GS, Rami-Mark C, James GM, Vanicek T, Gryglewski G et al (2019) Association of norepinephrine transporter methylation with in vivo NET expression and hyperactivity-impulsivity symptoms in ADHD measured with PET. Mol Psychiatry. https://doi.org/10.1038/s41380-019-0461-x

Sinusas AJ, Lazewatsky J, Brunetti J, Heller G, Srivastava A, Liu YH et al (2014) Biodistribution and radiation dosimetry of LMI1195: first-in-human study of a novel 18F-labeled tracer for imaging myocardial innervation. J Nucl Med 55(9):1445-1451

Skowronek C, Zange L, Lipp A (2019) Cardiac 123I-MIBG scintigraphy in neurodegenerative Parkinson syndromes: performance and pitfalls in clinical practice. Front Neurol 10:152. https://doi. org/10.3389/fneur.2019.00152

Solbach TF, Grube M, Fromm MF, Zolk O (2011) Organic cation transporter 3: expression in failing and nonfailing human heart and functional characterization. J Cardiovasc Pharmacol 58(4):409-417

Tack CJ, van Gurp PJ, Holmes C, Goldstein DS (2002) Local sympathetic denervation in painful diabetic neuropathy. Diabetes 51(12):3545-3553

Takano A, Gulyás B, Varrone A, Halldin C (2009) Comparative evaluations of norepinephrine transporter radioligands with reference tissue models in rhesus monkeys: (S, S)-[18F]FMeNERD2 and (S, S)-[11C]MeNER. Eur J Nucl Med Mol Imaging 36(11):1885-1891

Takano A, Gulyás B, Varrone A, Karlsson P, Schou M, Airaksinen $\mathrm{AJ}$ et al (2008a) Imaging the norepinephrine transporter with positron emission tomography: initial human studies with (S, S)[18F]FMeNER-D2. Eur J Nucl Med Mol Imaging 35(1):153-157

Takano A, Halldin C, Farde L (2013) SERT and NET occupancy by venlafaxine and milnacipran in nonhuman primates: a PET study. Psychopharmacology 226(1):147-153

Takano A, Halldin C, Varrone A, Karlsson P, Sjöholm N, Stubbs JB et al (2008b) Biodistribution and radiation dosimetry of the norepinephrine transporter radioligand (S, S)-[18F]FMeNER-D2: a human whole-body PET study. Eur J Nucl Med Mol Imaging 35(3):630-636

Takano A, Nag S, Gulyás B, Halldin C, Farde L (2011) NET occupancy by clomipramine and its active metabolite, desmethylclomipramine, in non-human primates in vivo. Psychopharmacology 216(2):279-286

Takano A, Varrone A, Gulyás B, Karlsson P, Tauscher J, Halldin C (2008c) Mapping of the norepinephrine transporter in the human brain using PET with $(\mathrm{S}, \mathrm{S})$-[18F]FMeNER-D2. Neuroimage 42(2):474-482

Takano H, Arakawa R, Nogami T, Suzuki M, Nagashima T, Fujiwara H et al (2014) Norepinephrine transporter occupancy by nortriptyline in patients with depression: a positron emission tomography study with (S, S)-[18F]FMeNER-D2. Int J Neuropsychopharmacol 17(4):553-560

Tatsumi M, Groshan K et al (1997) Pharmacological profile of antidepressants and related compounds at human monoamine transporters. Eur J Pharmacol 340(2-3):249-258

Timmers HJ, Carrasquillo JA, Whatley M, Eisenhofer G, Chen CC, Ling A et al (2007) Usefulness of standardized uptake values for distinguishing adrenal glands with pheochromocytoma from normal adrenal glands by use of $6-18 \mathrm{~F}$-fluorodopamine PET. $\mathrm{J}$ Nucl Med 48(12):1940-1944

Timmers HJ, Chen CC, Carrasquillo JA, Whatley M, Ling A, Havekes $\mathrm{B}$ et al (2009a) Comparison of 18F-fluoro-L-DOPA, 18F-fluorodeoxyglucose, and 18F-fluorodopamine PET and 123I-MIBG scintigraphy in the localization of pheochromocytoma and paraganglioma. J Clin Endocrinol Metab 94(12):4757-4767
Timmers HJ, Eisenhofer G, Carrasquillo JA, Chen CC, Whatley M, Ling A, Adams KT, Pacak K (2009b) Use of 6-[18F]-fluorodopamine positron emission tomography (PET) as first-line investigation for the diagnosis and localization of non-metastatic and metastatic phaeochromocytoma (PHEO). Clin Endocrinol (Oxf) 71(1):11-17

Tipre DN, Goldstein DS (2005) Cardiac and extracardiac sympathetic denervation in Parkinson's disease with orthostatic hypotension and in pure autonomic failure. J Nucl Med 46(11):1775-1781

Tokuda Y, Sakakibara M, Yoshinaga K, Yamada S, Kamiya K, Asakawa $\mathrm{N}$ et al (2019) Early therapeutic effects of adaptive servo-ventilation on cardiac sympathetic nervous function in patients with heart failure evaluated using a combination of 11C-HED PET and 123I-MIBG SPECT. J Nucl Cardiol 26(4):1079-1089

Travin MI (2017) Current Clinical Applications and Next Steps for Cardiac Innervation Imaging. Curr Cardiol Rep 19(1):1. https:// doi.org/10.1007/s11886-017-0817-2

Travin MI (2019) Expanding the clinical potential of cardiac radionuclide adrenergic imaging. J Nucl Cardiol. https://doi.org/10.1007/ s12350-019-01629-8

Tsuchimochi S, Tamaki N, Tadamura E, Kawamoto M, Fujita T, Yonekura Y, Konishi J (1995) Age and gender differences in normal myocardial adrenergic neuronal function evaluated by iodine-123-MIBG imaging. J Nucl Med 36(6):969-974

Ulke C, Rullmann M, Huang J, Luthardt J, Becker GA, Patt M et al (2019) Adult attention-deficit/hyperactivity disorder is associated with reduced norepinephrine transporter availability in right attention networks: a (S, S)-O-[11C]methylreboxetine positron emission tomography study. Transl Psychiatry 9(1):301

Vaidyanathan G, Affleck DJ, Alston KL, Welsh P, Zalutsky MR (2004) Catabolism of 4-fluoro-3-iodobenzylguanidine and meta-iodobenzylguanidine by SK-N-SH neuroblastoma cells. Nucl Med Commun 25(9):947-955

Vaidyanathan G, Affleck DJ, Zalutsky MR (1994) (4-[18F]fluoro3-iodobenzyl)guanidine, a potential MIBG analogue for positron emission tomography. J Med Chem 37:3655-3662

Vaidyanathan G, Affleck DJ, Zalutsky MR (1995) Validation of 4-[18F] fluoro-3-iodobenzylguanidine as a positron-emitting analog of MIBG. J Nucl Med 36:644-650

Vaidyanathan G, Affleck DJ, Zalutsky MR (1996) No-carrier-added (4-fluoro-3-[131I]iodobenzyl)guanidine and (3-[211At]astato4-fluorobenzyl)guanidine. Bioconjug Chem 7(1):102-107

Vaidyanathan G, McDouglad D, Koumarianou E, Choi J, Hens M, Zalutsky MR (2015) Synthesis and evaluation of 4-[18F]fluoropropoxy-3-iodobenzylguanidine ([18F]FPOIBG): a novel 18F-labeled analogue of MIBG. Nulc Med Biol 42(8):673-684

Vaidyanathan G, Zhao XG, Larsen RH, Zalutsky MR (1997a) 3-[211At]astato-4-fluorobenzylguanidine: a potential therapeutic agent with prolonged retention by neuroblastoma cells. Br J Cancer 76(2):226-233

Vaidyanathan G, Zhao XG, Strickland DK, Zalutsky MR (1997b) Nocarrier-added iodine-131-FIBG: evaluation of an MIBG analog. J Nucl Med 38(2):330-334

Van Dort ME, Tluczek L (2000) Synthesis and carbon-11 labeling of the stereoisomers of meta-hydroxyephedrine (HED) and metahydroxyseudoephedrine (HPED). J Labelled Comp Radiopharm 43:603-612

Vanicek T, Spies M, Rami-Mark C, Savli M, Höflich A, Kranz GS et al (2014) The norepinephrine transporter in attention-deficit/hyperactivity disorder investigated with positron emission tomography. JAMA Psychiatry 71(12):1340-1349

Vase KH, Peters D, Nielsen EØ, Alstrup AK, Bender D (2014) [11C] NS8880, a promising PET radiotracer targeting the norepinephrine transporter. Nucl Med Biol 41(9):758-764 
Vāvere AL, Neumann KD, Butch ER, Hu B, DiMagno SG, Snyder SE (2018) Improved, one-pot synthesis of 6-[18 F]fluorodopamine and quality control testing for use in patients with neuroblastoma. J Labelled Comp Radiopharm 61(14):1069-1080

Vettermann FJ, Rullmann M, Becker GA, Luthardt J, Zientek F, Patt $\mathrm{M}$ et al (2018) Noradrenaline transporter availability on [11C] MRB PET predicts weight loss success in highly obese adults. Eur J Nucl Med Mol Imaging 45(9):1618-1625

Vyakaranam AR, Crona J, Norlén O, Hellman P, Sundin A (2019) $11 \mathrm{C}$-hydroxy-ephedrine-PET/CT in the diagnosis of pheochromocytoma and paraganglioma. Cancers (Basel) 11(6):pii:E847

Wang T, Wu KY, Miner RC, Renaud JM, Beanlands RSB, deKemp RA (2018) Reproducible quantification of cardiac sympathetic innervation using graphical modeling of carbon-11-meta-hydroxyephedrine kinetics with dynamic PET-CT imaging. EJNMMI Res 8(1):63. https://doi.org/10.1186/s13550-018-0421-5

Werner RA, Rischpler C, Onthank D, Lapa C, Robinson S, Samnick S, Javadi M, Schwaiger M, Nekolla SG, Higuchi T (2015) Retention kinetics of the $18 \mathrm{~F}$-labeled sympathetic nerve PET tracer LMI1195: Comparison with 11C-hydroxyephedrine and 123I-MIBG. J Nucl Med 56:1429-1433

Werner RA, Maya Y, Rischpler C, Javadi MS, Fukushima K, Lapa C, Herrmann K, Higuchi T (2016) Sympathetic nerve damage and restoration after ischemia-reperfusion injury as assessed by (11)C-hydroxyephedrine. Eur J Nucl Med Mol Imaging 43(2):312-318

Werner RA, Chen X, Maya Y, Eissler C, Hirano M, Nose N, Wakabayashi H, Lapa C, Javadi MS, Higuchi T (2018) The impact of ageing on 11-Chydroxyephedrine uptake in the rat heart. Sci Rep 8:11120

Werner RA, Wakabayashi H, Chen X, Hayakawa N, Lapa C, Rowe SP, Javadi MS, Robinson S, Higuchi T (2019) Ventricular distribution pattern of the novel sympathetic nerve PET radiotracer 18F-LMI1195 in rabbit hearts. Sci Rep 9(1):17026

Wong KK, Raffel DM, Bohnen NI, Altinok G, Gilman S, Frey KA (2017) 2-Year natural decline of cardiac sympathetic innervation in idiopathic Parkinson Disease studied with 11C-hydroxyephedrine PET. J Nucl Med 58(2):326-331

Wu X, Kekuda R, Huang W, Fei YJ, Leibach FH, Chen J, Conway SJ, Ganapathy V (1998) Identity of the organic cation transporter OCT3 as the extraneuronal monoamine transporter (uptake2) and evidence for the expression of the transporter in the brain. J Biol Chem 273(49):32776-32786
Wu KY, Zelt JGE, Wang T, Dinculescu V, Miner R, Lapierre C et al (2019) Reliable quantification of myocardial sympathetic innervation and regional denervation using [11C]meta-hydroxyephedrine PET. Eur J Nucl Med Mol Imaging. https://doi.org/10.1007/ s00259-019-04629-5

Yamaguchi A, Hanaoka H, Higuchi T, Tsushima Y (2018) Radiolabeled (4-fluoro-3-iodobenzyl)guanidine improves imaging and targeted radionuclide therapy of norepinephrine transporterexpressing tumors. J Nucl Med 59(5):815-821

Yu M, Bozek J, Lamoy M, Guaraldi M, Silva P, Kagan M et al (2011) Evaluation of LMI1195, a novel 18F-labeled cardiac neuronal PET imaging agent, in cells and animal models. Circ Cardiovasc Imaging 4(4):435-443

Yu M, Bozek J, Lamoy M, Kagan M, Benites P, Onthank D, Robinson SP (2012) LMI1195 PET imaging in evaluation of regional cardiac sympathetic denervation and its potential role in antiarrhythmic drug treatment. Eur J Nucl Med Mol Imaging 39(12):1910-1919

Yu M, Bozek J, Kagan M, Guaraldi M, Silva P, Azure M, Onthank D, Robinson SP (2013) Cardiac retention of PET neuronal imaging agent LMI1195 in different species: impact of norepinephrine uptake-1 and -2 transporters. Nucl Med Biol 40(5):682-688

Zelt J, Renaud J, Mielniczuk L, Garrard L, Walter O, Guo A, deKamp R, Beanlands R (2018) Fluorine-18 LMI1195 positron emission tomography provides accurate measure of cardiac sympathetic innervation compared to carbon-11 hydroxyephedrine. J Am Coll Cardiol. https://doi.org/10.1016/s0735-1097(18)32023-0

Zhang H, Huang R, Pillarsetty N, Thorek DL, Vaidyanathan G, Serganova I, Blasberg RG, Lewis JS (2014a) Synthesis and evaluation of $18 \mathrm{~F}$-labeled benzylguanidine analogs for targeting the human norepinephrine transporter. Eur J Nucl Med Mol Imaging 41(2):322-332

Zhang H, Huang R, Cheung NK, Guo H, Zanzonico PB, Thaler HT, Lewis JS, Blasberg RG (2014b) Imaging the norepinephrine transporter in neuroblastoma: a comparison of [18F]-MFBG and 123I-MIBG. Clin Cancer Res 20(8):2182-2191

Zlatopolskiy BD, Zischler J, Urusova EA, Endepols H, Kordys E, Frauendorf H, Mottaghy FM, Neumaier B (2015) A practical onepot synthesis of positron emission tomography (PET) tracers via Nickel-mediated radiofluorination. ChemistryOpen 4(4):457-462

Publisher's Note Springer Nature remains neutral with regard to jurisdictional claims in published maps and institutional affiliations. 